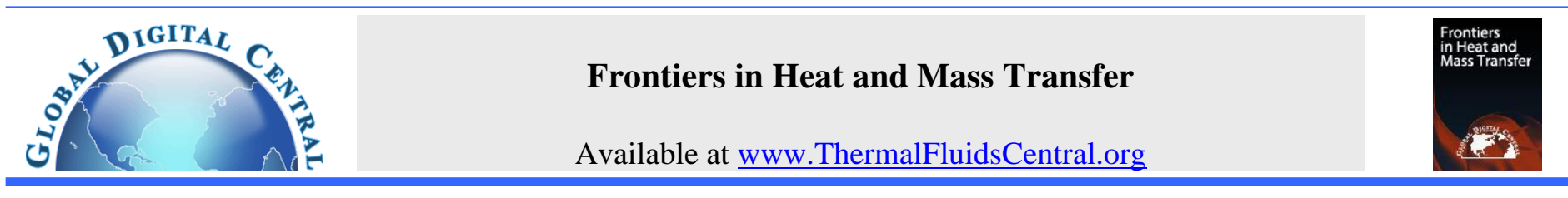

\title{
EFFECT OF WALL THERMAL CONDUCTIVITY ON HYDROGEN- ASSISTED CATALYTIC IGNITION CHARACTERISTICS OF PROPANE- AIR AT MICRO-SCALES IN DIFFERENT FEEDING MODES
}

\author{
Junjie Chen", Xuhui Gao, Deguang Xu \\ School of Mechanical and Power Engineering, Henan Polytechnic University, Jiaozuo, Henan, 454000, China
}

\begin{abstract}
Effect of wall thermal conductivity on hydrogen self-ignition and hydrogen-assisted ignition of propane-air mixtures in different feeding modes from ambient cold-start conditions were investigated numerically with chemical kinetic model in $\mathrm{Pt} / \gamma-\mathrm{Al}_{2} \mathrm{O}_{3}$ catalytic micro-combustors. For the steady and transient state, effect of wall thermal conductivity on self-ignition characteristics of lean hydrogen-air mixtures was presented, and hydrogenassisted combustion of propane-air mixtures was investigated numerically in the co-feed mode and the sequential feed mode. The computational results indicate the large thermal inertia of the micro-combustor solid structure leads to slow temperature dynamics, and transient response is dominated by the thermal inertia. The heat localization in poorly conducting walls leads to fast ignition and shorter steady state time. In general, the concentration of hydrogen required for propane ignition increased with increasing wall thermal conductivity, decreasing inlet velocity, and decreasing inlet equivalence ratio of propane-air mixtures. In the co-feed mode, the combustion characteristics of hydrogen-assisted propane qualitatively resemble the selectively preheating initial portion of the combustion chamber wall. In the sequential feed mode, the time taken to reach steady state, the hydrogen cut-off time, the propane ignition time and the cumulative propane emissions increased with increasing wall thermal conductivity; the ignition characteristics are similar to partially preheating the initial segment for low and moderate wall thermal conductivity values $(0.5$ and $20 \mathrm{~W} / \mathrm{m} \cdot \mathrm{K})$; however, the ignition characteristics are close to completely heating the micro-combustor wall for high wall thermal conductivity values $(200 \mathrm{~W} / \mathrm{m} \cdot \mathrm{K})$.
\end{abstract}

Keywords: Hydrogen-assisted ignition; Self-ignition; Thermal conductivity; Micro-combustion; Catalytic combustion

\section{INTRODUCTION}

In recent years, hydrocarbon-fueled catalytic micro-combustors have been the focus of intense efforts for a variety of portable power production systems with demonstrated energy densities considerably higher than those obtained with state-of-the-art Li-ion batteries $\mathrm{Ju}$ and Maruta, 2011). Applications range from catalytic micro-thrusters for space applications (Volchko et al., 2006), to micro-reactors used for fuel reforming in micro solid oxide fuel cells (Cheekatamarla et al., 2008), and to scaled-down thermal engines, wherein catalytic microcombustors are used for direct chemical-to-thermal energy conversion (Gomez et al., 2007; Karim et al., 2008). Noble metal catalysts (such as $\mathrm{Pt}, \mathrm{Pd}, \mathrm{Rh}$, etc.) are employed in most cases, because of their superior activity for the total oxidation and reforming of hydrocarbons at modest reactor temperatures (Aryafar and Zaera, 1997).

Various configurations of catalytic micro-combustors have so far been introduced. For instance, heat recirculating Swiss-roll burners make use of the excess exhaust gas enthalpy for increased combustion stability (Ahn et al., 2005), while conventional straight catalytic channels (Federici et al., 2009) and catalytic foam structures (Jin and Kwon, 2009) have also been employed in micro-combustors study. The aforementioned studies have focused on thermal management and combustion efficiency. On the other hand, numerical simulations of catalytic micro-combustors encompass investigations of combustion stability and performance using 1-D models with lumped heat and mass transport coefficients (Kaisare et al., 2008; Ronney, 2003), 2-D models with detailed chemistry kinetics but without heat conduction in the solid wall (Maruta et al., 2002), 2-D models with simplified chemistry kinetics accounting for heat conduction in the solid (Deshmukh et al., 2004; Stefanidis and Vlachos, 2009), and finally full 2-D CFD models where all relevant heat transfer mechanisms in the solid (including heat conduction and surface radiation heat transfer) along with detailed homogeneous and heterogeneous chemistry kinetics are accounted (Karagiannidis et al., 2007). It is emphasized that although Sherwood and Nusselt number empirical correlations have been proposed for laminar channel flows with surface catalytic reactions (Groppi et al., 1995), their universal applicability under different reacting conditions is not warranted. Moreover, 1-D models fail to describe homogeneous combustion due to the strong dependence of homogeneous reactions on the boundary layer profiles of temperature and species (Mantzaras and Benz, 1999).

Many experimental and numerical investigations which have been conducted are concentrated on the effects of some crucial options such as micro-tube/channel geometry (Kaisare and Vlachos, 2007; Kim and Maruta, 2006; Norton and Vlachos, 2004), heat loss (Hua et al., 2005; Norton and Vlachos, 2004), thermal and radical quenching (Kim et al., 2006), fluid flow characteristic and equivalence ratio (Hua et al., 2005; Zhang et al., 2007), and pre-heating of fresh entrance reactive mixture (Hua et al., 2005; Ju and Choi, 2003; Kaisare and Vlachos, 2007; Leach and Cadou, 2005; Norton and Vlachos, 2003; Raimondeau et al., 2002) on combustion phenomena in micro-combustors. As results of many investigations, it can be inferred that the micro-combustor

"Corresponding author.Email: comcjj@163.com 
geometry such as wall thickness (Hua et al., 2005), combustor diameter (axisymmetric models) or distance between two planar plates (2D models), heat transfer surface (Kaisare and Vlachos, 2007) and inserting backward facing-step (Ju and Choi, 2003) play crucial roles in establishing a stable and efficient combustion in a micro-tube/channel. This phenomena may occur due to several reasons such as heat loss variations, heat transfer from post-flame to pre-flame zone (Hua et al., 2005; Kaisare and Vlachos, 2007; Leach and Cadou, 2005), the increment of reactive mixture residence time (Norton and Vlachos, 2003) and enhancement of mixing process, respectively. Also, some chemical and physical properties of the micro-combustor wall and the inlet mixture such as fuel type (Norton and Vlachos, 2003), wall thermal conductivity (Baigmohammadi et al., 2013; Norton and Vlachos, 2003, 2004; Raimondeau et al., 2002; Rana et al., 2014; Veeraragavan and Cadou, 2011; Zarvandi et al., 2012; Zhou et al., 2009), equivalence ratio and inlet velocity can influence combustion process in micro-combustors. Therefore, variation of the wall thermal conductivity and its physical properties can govern the combustion by proper pre-heating of fresh incoming mixture (Raimondeau et al., 2002) or thermal and radical species quenching processes (Kim et al., 2006).

The wall thermal conductivity plays a vital role in combustion characteristics (Baigmohammadi et al., 2013; Norton and Vlachos, 2003, 2004; Rana et al., 2014; Zhou et al., 2009). Low wall thermal conductivity limits the upstream heat transfer through the wall, which limits the preheating of the feed, inhibiting the onset of combustion, and causes blowout. Low wall thermal conductivity also causes hot spots of high temperatures within the wall, which can lead to mechanical failure. High thermal conductivity walls are essentially isothermal and have lower temperatures. However, they offer a larger hot area for external heat transfer and become susceptible to spatially global-like extinction (Norton and Vlachos, 2003). When a low-power device is being designed, more insulating materials should be favored to minimize external heat losses. Conversely, a high-power device would favor more conductive materials (Rana et al., 2014; Zhou et al., 2009). Furthermore, the wall material thermal conductivity plays a competing role in flame stability (Norton and Vlachos, 2003, 2004; Raimondeau et al., 2002). Walls transfer heat upstream for ignition of the cold incoming gases but at the same time are responsible for heat losses. Consequently, there is an optimum wall thermal conductivity in terms of flame stability, which appears to be that of common ceramics such as alumina and silica (Norton and Vlachos, 2005; Norton et al., 2004). Regarding material lifetimes, higher wall thermal conductivities reduce the wall temperature gradients and hotspots and should be preferred (Kaisare and Vlachos, 2007).

Until recently, most of the numerical and experimental investigations have focused on the steady-state performance of catalytic micro-combustors and micro-reformers (Fanaee and Esfahani, 2014; Hsueh et al., 2011; Leu et al., 2013; Sari and Zohrabian, 2014). On the other hand, a limited number of investigates investigated the transient response and particularly the light-off (ignition process). Ignition at problem-specific operating conditions is key to the overall acceptance of given micro-combustors design. Furthermore, ignition determines the time length required for start-up and the associated pollutant emissions during this period. The start-up of a propane-fueled, platinum-coated micro-combustor, with added hydrogen to facilitate light-off, has been demonstrated experimentally (Norton and Vlachos, 2005), while the self-ignition of methanol-air mixtures in similar micro-reactors coupled to thermo-electrical devices have been investigated (Karim et al., 2008). The former work mainly focused on developing a start-up strategy for the specific micro-combustor and micro-reactor, while the latter demonstrated the feasibility of integrating a self-igniting catalytic micro-combustor to a power generating system. Similarly, catalytic ignition and extinction in partial oxidation of methane-air mixtures, diluted with exhaust gas recycle, have been investigated numerically and experimentally in rhodium-coated honeycomb reactors for gasturbine applications (Schneider et al., 2008). Although the last investigation did not pertain to micro-reactors, it nevertheless addressed crucial catalytic ignition requirements in accordance to stringent residence time limitations and reactor inlet temperature.

The study of hydrogen-assisted catalytic ignition necessarily starts with the fuels used. The hydrogen-assisted catalytic ignition characteristics of methane in a Pt-coated monolith reactor have been investigated experimentally (Deutschmann et al., 2000), achieving ignition with a minimum hydrogen concentration of $4.75 \%$ (on a molar basis). The experimental results showed that the amount of hydrogen required for ignition increases as methane concentration is decreased. Also, during ignition, the main effect of hydrogen is thermal. The hydrogen ignited first on catalyst surface, and then the temperature of mixtures increased from room temperature to ignition point. A kind of catalytic micro-channel burner have been fabricated to investigate hydrogen catalytic combustion and the characteristics of propane in hydrogen-assisted catalytic ignition (Norton and Vlachos, 2005; Norton et al., 2004). A minimum hydrogen concentration of $3.6 \%$ mole fraction was found to be required. They found that the ignition process had two stages: hydrogen ignition, and then propane ignition. At low hydrogen concentrations, propane kinetically inhibits hydrogen catalytic combustion.

Most current prototypes of micro-combustors depend on exterior heating to generate energy for ignition, and the additional equipment necessary to power the exterior heaters can negate mass advantages of micro-combustors. In this work, effect of wall thermal conductivity on hydrogen self-ignition and hydrogen-assisted ignition of propane-air mixtures in different feeding modes from ambient cold-start conditions are investigated numerically in catalytic micro-combustors. Moreover, for the steady and transient state, a reduced-order reaction model is employed to examine the ignition characteristics of hydrogen. Finally, the hydrogen-assisted combustion of propane-air mixtures is investigated numerically in different operation modes of fuel feed.

\section{NUMERICAL MODELS AND SIMULATION APPROACH}

\subsection{Model Geometry and Mesh}

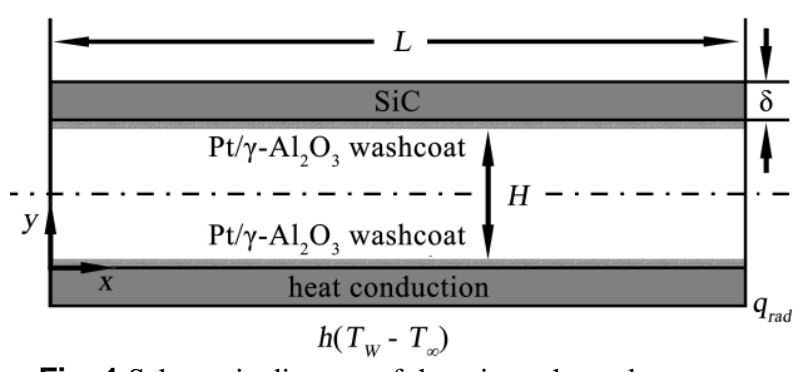

Fig. 1 Schematic diagram of the micro-channel geometry.

A schematic diagram of the catalytic micro-combustor modeled is shown in Fig. 1. The kinetics module plug-in for FLUENT ${ }^{\circledR}$ Release 6.3 was employed to simulate the flow and combustion of hydrogenpropane-air mixtures in the plane micro-channel of length $L=20.0 \mathrm{~mm}$, height $H=0.2 \mathrm{~mm}$, and solid wall thickness $\delta=0.2 \mathrm{~mm}$. Inner horizontal surfaces contained $\mathrm{Pt} / \gamma-\mathrm{Al}_{2} \mathrm{O}_{3}$ catalyst washcoat. The properties of $\mathrm{Pt} / \gamma-\mathrm{Al}_{2} \mathrm{O}_{3}$ supported noble metal catalysts are shown in Table 1. In the present work, in order to couple heat transfer, fluid dynamics, and hetero-/homogeneous chemical kinetics, FLUENTKINETICS was employed to simulate the catalytic combustion process.

Table 1 The properties of $\mathrm{Pt} / \gamma-\mathrm{Al}_{2} \mathrm{O}_{3}$ catalyst washcoat.

\begin{tabular}{|l|l|}
\hline Property & Value \\
\hline Catalyst surface site density $\Gamma\left(\mathrm{mol} / \mathrm{cm}^{2}\right)$ & $2.7 \times 10^{-9}$ \\
\hline Average pore diameter $d_{\text {pore }}(\mathrm{m})$ & $2.08 \times 10^{-8}$ \\
\hline Catalyst porosity $\varepsilon_{\text {cat }}$ & 0.4 \\
\hline Catalyst tortuosity $\tau_{\text {cat }}$ & 8.0 \\
\hline
\end{tabular}




\subsection{Chemical Kinetics for Hydrogen Combustion}

The chemical kinetics (Bui et al., 1997) for the combustion of hydrogen-air is adopted, which developed the model via the hierarchical model reduction of 13-step surface catalytic reaction mechanism. The resulting reaction rate of combustion is given by the following reduced-order reaction rate kinetics:

$-r_{\text {cat, } \mathrm{H}_{2}}=\eta A_{0} T^{\beta} e^{\frac{-E_{a, \mathrm{H}_{2}}^{a d s}}{\mathrm{R} T}} C_{\mathrm{H}_{2}}$

Where the effectiveness factor $\eta$ is 1 , the pre-exponential factor $A_{0}$ is $1280 \mathrm{~cm} \mathrm{~K}^{-0.5} \cdot \mathrm{s}^{-1}$, the temperature exponent $\beta$ is 0.5 , and the activation energy $E_{\mathrm{a}, \mathrm{H} 2}$ (ads) is $0 \mathrm{~kJ} \cdot \mathrm{mol}^{-1}$ because of hydrogen adsorption is the non-activated process (Bui et al., 1997).

Norton et al. (2004) reported that homogeneous combustion of near-stoichiometric hydrogen-air mixtures occurs in the larger gap size of $1.0 \mathrm{~mm}$, but not for the smaller gap size of $0.25 \mathrm{~mm}$. Even in the 1.0 $\mathrm{mm}$ micro-combustor, hydrogen light-off in gas phase was observed beyond the equivalence ratio of 0.33 . Moreover, Norton et al. (2004) also reported that this kinetic model is valid for the concentration of hydrogen in the range of the equivalence ratio $0.008<\varphi_{\mathrm{H} 2}<0.424$. Mantzaras (2008) observed hydrogen light-off in gas phase for the equivalence ratio of 0.2 in $1.2 \mathrm{~mm}$ diameter micro-channels. Therefore, in this work, homogeneous combustion of hydrogen-air mixtures is neglected and numerical simulations are restricted for hydrogen concentrations below the equivalence ratio of 0.2 .

\subsection{Chemical Kinetics for Propane Combustion}

$\mathrm{Pt} / \gamma-\mathrm{Al}_{2} \mathrm{O}_{3}$ catalysts were adopted for catalytic micro-combustion of propane-air mixtures. The reason is that the propane conversion of noble metal catalysts decreases in the order $\mathrm{Pt} / \gamma-\mathrm{Al}_{2} \mathrm{O}_{3}>\mathrm{Pd} / \gamma-\mathrm{Al}_{2} \mathrm{O}_{3}>$ $\mathrm{Rh} / \gamma-\mathrm{Al}_{2} \mathrm{O}_{3}$ at the stoichiometric propane-oxygen ratio (Men et al., 2009). The reduced-order reaction rate kinetics for catalytic combustion of propane-air are as follows:

$r_{\text {cat }, \mathrm{C}_{3} \mathrm{H}_{8}}=\frac{k_{\mathrm{C}_{3} \mathrm{H}_{8}}^{a d s} C_{\mathrm{s}, \mathrm{C}_{3} \mathrm{H}_{8}}}{\left(1+\sqrt{\frac{k_{\mathrm{O}_{2}}^{a d s} C_{\mathrm{s}, \mathrm{O}_{2}}}{k_{\mathrm{O}_{2}}^{\text {des }}}}\right)^{2}}$

Where $r_{\mathrm{cat}, \mathrm{C} 3 \mathrm{H} 8}$ is the surface catalytic reaction rate of propane. $C s, i$ is concentration of adsorbed species $i . k_{i}$ is adsorption or desorption rate constant of species $i$, and determined as follows:

$$
\begin{aligned}
& k_{i}^{a d s}=\frac{s_{0}}{\Gamma} \sqrt{\frac{\mathrm{R} T}{2 \pi M_{i}}}\left(\frac{T}{T_{r e f}}\right)^{\beta_{i}^{a d s}} e^{\frac{-E_{a, i}^{\text {ads }}}{\mathrm{RT}}} \\
& k_{i}^{\text {des }}=A_{0}\left(\frac{T}{T_{\text {ref }}}\right)^{\beta_{i}^{d e s}} e^{\frac{-E_{a, i}^{d e s}}{\mathrm{RT}}}
\end{aligned}
$$

Where $s_{0}$ is the sticking coefficient. $\Gamma$ is $\mathrm{Pt} / \gamma-\mathrm{Al}_{2} \mathrm{O}_{3}$ catalyst surface site density. $M_{i}$ is the molecular weight of species $i$. $T_{r e f}$ is the temperature of reference conditions. The values of kinetic parameters for the catalytic combustion of lean propane are shown in Table 2.

Table 2 Kinetic parameters for the catalytic combustion of lean propane over $\mathrm{Pt} / \gamma-\mathrm{Al}_{2} \mathrm{O}_{3}$.

\begin{tabular}{|c|c|c|c|}
\hline & $A_{0}\left(\mathrm{~s}^{-1}\right)$ or $s_{0}$ & $\beta$ & $E_{a}\left(\mathrm{kcal} \cdot \mathrm{mol}^{-1}\right)$ \\
\hline $\mathrm{C}_{3} \mathrm{H}_{8}$ adsorption & 0.06 & 0.154 & 4 \\
\hline $\mathrm{O}_{2}$ adsorption & 0.0542 & 0.766 & 0 \\
\hline $\mathrm{O}_{2}$ desorption & $8.41 \times 10^{12}$ & -0.796 & $*$ \\
\hline
\end{tabular}

* $E_{a, \mathrm{O}_{2}}^{\text {des }}=52.8-\frac{2.3 T}{300}-32.0 \theta_{\mathrm{O}}$.

Surface area factor $\eta=1.7$, temperature of reference conditions $T_{r e f}=$ $300 \mathrm{~K}$.

The activation energy $E_{\mathrm{a}, \mathrm{O} 2}(\mathrm{des})$ of oxygen desorption depends on the coverage $\theta_{\mathrm{o}}$. of oxygen radical, which is calculated as follows:

$$
\theta_{\mathrm{O}}=1-\frac{1}{\left(1+\sqrt{\frac{k_{\mathrm{O}_{2}}^{\text {ads }} C_{s, \mathrm{O}_{2}}}{k_{\mathrm{O}_{2}}^{\text {des }}}}\right)}
$$

\subsection{Boundary Conditions}

The incoming flow of hydrogen-air or hydrogen-propane-air mixtures was fully premixed and have uniform inlet temperature of $300 \mathrm{~K}$. The thermal boundary condition on the wall is the heat loss to the ambient air. The heat losses to the surroundings are calculated using the following equation:

$q=h\left(T_{w, o}-T_{\infty}\right)+\varepsilon \delta\left(T_{w, o}{ }^{4}-T_{\infty}^{4}\right)$

Where the exterior convective heat transfer coefficient $h$ is $20 \mathrm{~W} / \mathrm{m}^{2} \cdot \mathrm{K}$ in this study. $T_{w, o}$ is the temperature at the exterior wall surface. The ambient temperature $T_{\infty}$ is $300 \mathrm{~K}$. The solid wall emissivity $\varepsilon$ is taken to be 0.8 and $\delta$ is the Stefan-Boltzmann constant.

\subsection{Computation scheme}

For the steady state simulation, the mass, momentum, energy and species conservation equations are solved implicitly with the 2D steadystate double-precision segregated solver using the under-relaxation method. The aforementioned conservation equations are discretized using second-order upwind scheme. The "SIMPLE" algorithm is used to couple the pressure and velocity. The fluid density is calculated using the ideal gas law. The fluid thermal conductivity, specific heat, and viscosity are calculated using the mass fraction weighted average of species properties. The species specific heat is calculated using the piecewise polynomial fit of temperature. The uniform grid size of 0.005 $\mathrm{mm}$ was used to mesh the computational domain. Grid-independence of the solution was tested. The convergence of the CFD simulation was judged based on the residuals of all governing equations. The simulation results are achieved with residuals smaller than $1.0 \times 10^{-6}$.

For the transient state simulation, the "PISO" algorithm is used to couple the pressure and velocity. The transient solid equation was solved with a second order accurate, fully implicit scheme by using a quadratic backward time discretization. The coupled flow and solid phases were solved iteratively and convergence was achieved at each time step when the solid temperature did not vary at any position along the wall by more than $10^{-5} \mathrm{~K}$ (Karagiannidis and Mantzaras, 2010). Catalytic chemical reaction times are assumed to be shorter than the heat conduction times in the solid, so as to ensure chemical equilibration at the local wall temperature during an integration time step of the solid. The time step $\Delta t=50.0 \mathrm{~ms}$ used in this work had to be longer than the chemical time scales present during catalytic ignition in micro-combustors.

The simulations were performed on a high-performance cluster consisting of $4 \times$ E5-2600 processors and 48 GB of RAM. Parallel processing was used, and the message passing interface (MPI) was used to transmit information between nodes. For the transient state simulation, the calculation time of each simulation varied between 40.0 minutes and 8 hours, depending on the difficulty of the problem.

\section{EFFECT OF WALL THERMAL CONDUCTIVITY ON CATALYTIC IGNITION CHARACTERISTICS OF HYDROGEN}

\subsection{Steady State Behavior}

Despite the high diffusivity of hydrogen, the catalytic combustion of hydrogen-air at micro-scales is diffusion limited (Kamada et al., 2014; Schultze et al., 2013; Sen and Avci, 2014; Yang et al., 2014). The incoming hydrogen-air mixtures was fully premixed with the equivalence ratio of 0.2 . The effect of inlet velocity on the temperature along central axis and interior wall as well as the hydrogen conversion for adiabatic and non-adiabatic micro-combustors at steady state are 
shown in Fig. 2-4. The micro-combustion occurs close to the inlet section and only a fraction of micro-combustor length is required to attain complete hydrogen conversion, even for higher velocity case. The maximum temperature is attained at the beginning of the interior wall, by reason of the surface catalytic reaction. The maximum temperature on the interior wall increases as the inlet velocity is increased or heat transfer coefficient is decreased. In the case of non-adiabatic microcombustors, the upstream interior wall gets heated up because of the surface catalytic reaction, whereas the net heat loss to the ambience occurs in the downstream section. Therefore, for the moderate to high heat losses case, the direction of heat transfer is from the solid wall to the gas phase in upstream section because of the surface catalytic reaction, whereas the direction reverses in the downstream section by reason of the heat losses. In adiabatic micro-combustors or at higher inlet velocity, the aforementioned reversal is not observed.

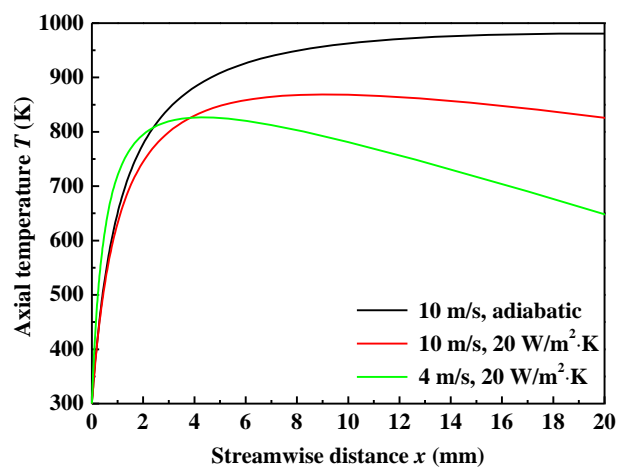

Fig. 2 Temperature along central axis for adiabatic and non-adiabatic micro-combustors at steady state.

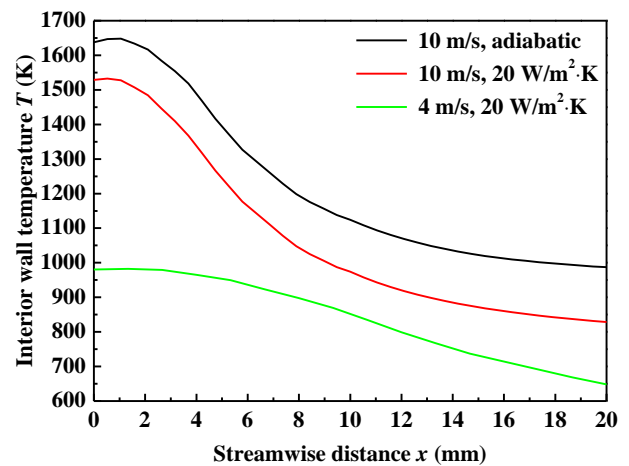

Fig. 3 Temperature along interior wall for adiabatic and non-adiabatic micro-combustors at steady state.

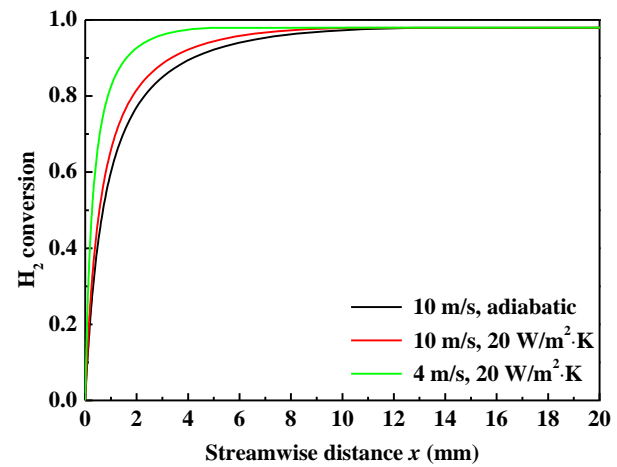

Fig. 4 Hydrogen conversion for adiabatic and non-adiabatic microcombustors at steady state.

The wall thermal conductivity also affects the overall temperature distribution in micro-combustors. For lower wall thermal conductivities, the significant temperature gradients exist as observed, whereas the interior wall temperature profiles are nearly flat for the highly conducting walls in Fig. 5-6.

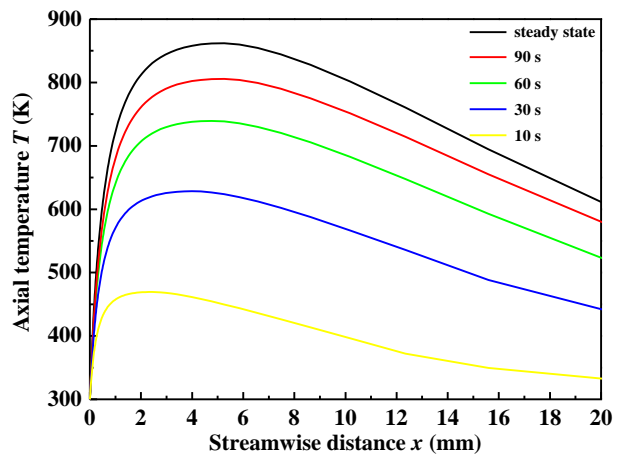

(a) $k_{s}=0.5 \mathrm{~W} / \mathrm{m} \cdot \mathrm{K}$

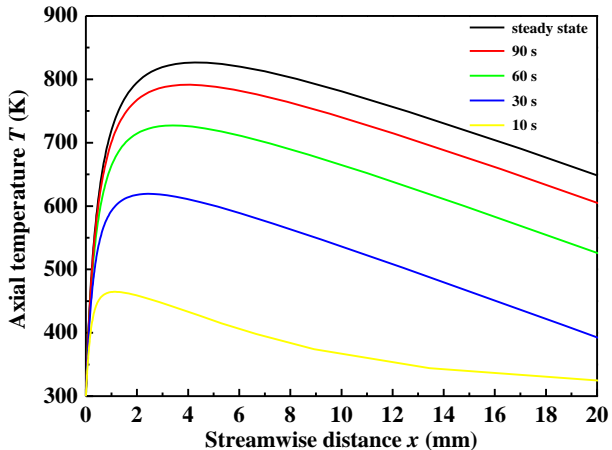

(b) $k_{s}=20 \mathrm{~W} / \mathrm{m} \cdot \mathrm{K}$

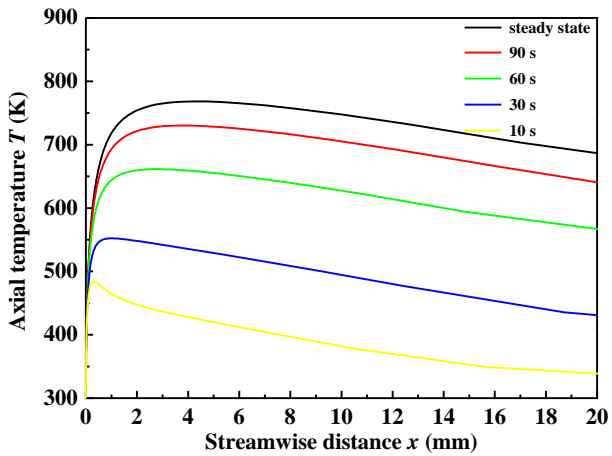

(c) $k_{s}=200 \mathrm{~W} / \mathrm{m} \cdot \mathrm{K}$

Fig. 5 Transient evolution of the central axial temperature profiles in the gas phase for hydrogen catalytic ignition for different wall thermal conductivities. $\varphi$ (hydrogen) $=0.7, u_{0}=2 \mathrm{~m} / \mathrm{s}, h=20$ $\mathrm{W} / \mathrm{m}^{2} \cdot \mathrm{K}$, and $k_{s}=20 \mathrm{~W} / \mathrm{m} \cdot \mathrm{K}$.

\subsection{Transient Behavior}

In the present work, the primary purpose is to analyze the transient response of the micro-combustor. The micro-combustor initially contains only air and starting at ambient conditions of $300 \mathrm{~K}$. The premixed hydrogen-air mixtures is fed starting at the time $t=0$ and the desired inlet velocity of $4 \mathrm{~m} / \mathrm{s}$ and equivalence ratio of 0.2 . Numerical simulations are run for enough time to ensure the reaction system reaches steady state. Norton and Vlachos (2004) investigated numerically the effects of dimensions, external heat losses, wall thermal conductivity, and operating conditions on combustion characteristics and the steady-state, self-sustained flame stability of propane-air. The result shown that the wall thermal conductivity is vital in determining the flame stability, as the walls are responsible for the majority of the external heat losses as well as the upstream heat transfer. Therefore, the effects of the wall thermal conductivity on the ignition characteristics of propane-air are investigated in this work. 


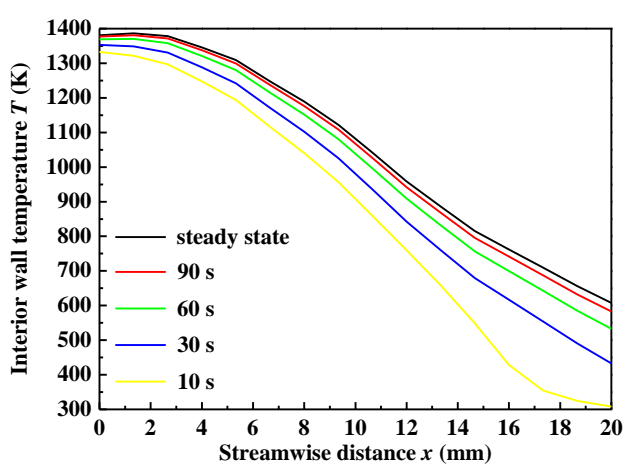

(a) $k_{s}=0.5 \mathrm{~W} / \mathrm{m} \cdot \mathrm{K}$

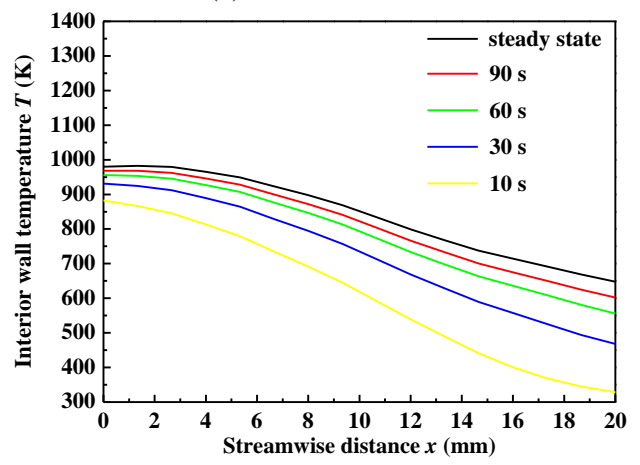

(b) $k_{s}=20 \mathrm{~W} / \mathrm{m} \cdot \mathrm{K}$

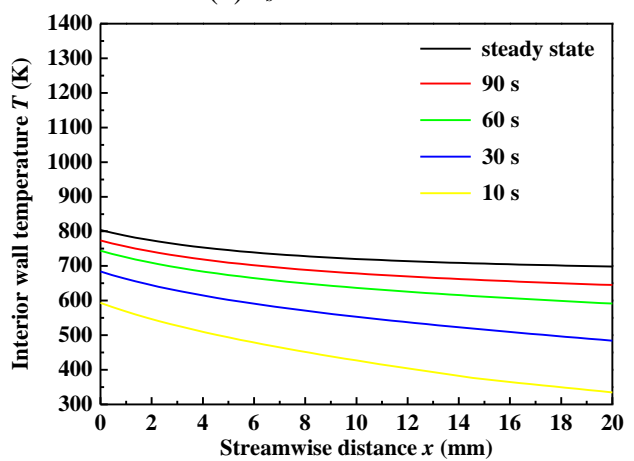

(c) $k_{s}=200 \mathrm{~W} / \mathrm{m} \cdot \mathrm{K}$

Fig. 6 Transient evolution of the interior wall temperature profiles on the wall for hydrogen catalytic ignition for different wall thermal conductivities. $\varphi$ (hydrogen) $=0.7, u_{0}=2 \mathrm{~m} / \mathrm{s}, h=20$ $\mathrm{W} / \mathrm{m}^{2} \cdot \mathrm{K}$, and $k_{s}=20 \mathrm{~W} / \mathrm{m} \cdot \mathrm{K}$.

For low $(0.5 \mathrm{~W} / \mathrm{m} \cdot \mathrm{K})$, moderate $(20 \mathrm{~W} / \mathrm{m} \cdot \mathrm{K})$ and high $(200$ $\mathrm{W} / \mathrm{m} \cdot \mathrm{K}$ ) thermal conductivities of wall material, the temporal responses of the central axial and the interior wall temperature profiles from ambient cold-start conditions are shown in Fig. 5 and 6, respectively. The thermal conductivities of wall material have a significant effect on the temperature distribution; in the bulk gas and the wall, the large temperature gradients exist in low thermal conductivity walls whereas the temperature profiles are nearly flat for the highly conducting walls. However, the hydrogen conversion is not affected by the thermal conductivity. In all cases, front-end ignition is observed and hydrogen conversion attain the steady state profile in Fig. 4 in less than 1.0 s. Due to the hydrogen conversion profile does not change for most of the simulation time after about $1.0 \mathrm{~s}$, the aforementioned behavior is often referred to as pseudo-steady-state. Compared with the reaction and diffusion processes, the large thermal inertia of the micro-combustor solid structure leads to slow temperature dynamics, and transient response is dominated by the thermal inertia (Kaisare et al., 2005; Kikas et al., 2003).

The variations of the outlet temperature in gas phase for different wall thermal conductivities are shown in Fig. 7. The time when the micro-combustor reaches steady state is denoted by symbols. The symbols time is defined at which the maximum deviation of the outlet temperature is less than $0.5 \mathrm{~K}$ from the steady state values. The steady state time increases as the wall thermal conductivity is increased. For low wall thermal conductivity, a high temperature gradient exists on the wall, which will make the homogeneous combustion shift upstream and the micro-combustor will have a higher peak temperature (Chen et al., 2007). On the contrary, for high wall thermal conductivity, a low temperature gradient on the wall will make the homogeneous combustion shift downstream and the micro-combustor will have a higher outlet temperature. For different inlet velocities and wall thermal conductivities, the time taken to reach steady state are shown in Fig. 8. As the inlet velocity is increased, the steady state time decreases due to the maximum wall temperature increase and the net energy supplied. As observed in Fig. 7-8, for lower wall thermal conductivity, the steady state time is shorter. The reason is that the heat localization in poorly conducting walls leads to fast ignition. At low inlet velocity, the effect of wall thermal conductivity on the steady state time is especially significant; as the inlet velocity is increased, the effect diminishes as a result of the increased convective heat transfer.

In general, the catalytic combustion reaches pseudo-steady state instantaneously; the combustion region is a short zone near the inlet section; and the higher inlet velocities lead to faster transient response.

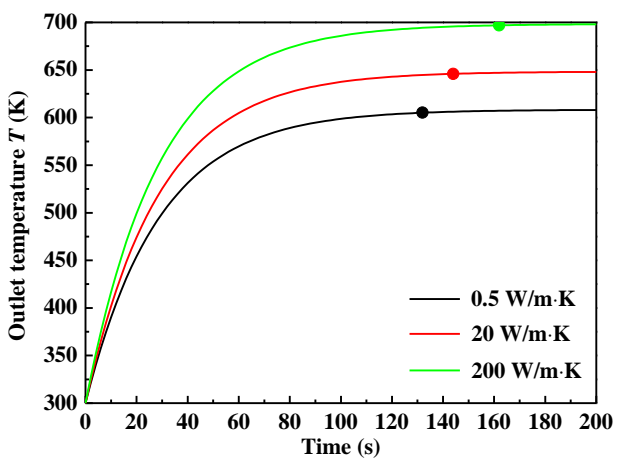

Fig. 7 Outlet temperature in gas phase versus time for different wall thermal conductivities. The symbols represent the time when the micro-combustor reaches steady state.

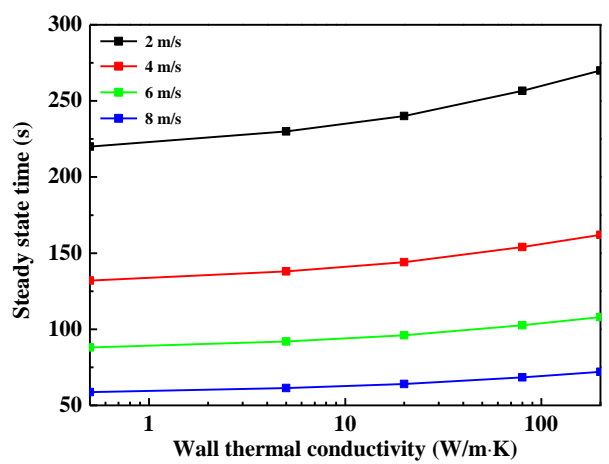

Fig. 8 The entire time required to reach steady state from initial conditions for different inlet velocities and wall thermal conductivities.

\section{EFFECT OF WALL THERMAL CONDUCTIVITY ON CATALYTIC IGNITION CHARACTERISTICS OF HYDROGEN-ASSISTED PROPANE}

The self-ignition nature of hydrogen-air mixtures at micro-scales of ceramic burners offers an opportunity to self-ignite hydrocarbons. This concept may be a way toward elimination of ignition sources from micro-scale devices leading to further reduction of system size. Furthermore, since hydrogen is a main target for fuel cell applications, one can envision storage of small amounts of hydrogen during device operation from reforming of hydrocarbons that is subsequently used for 
startup. Here, we explore the feasibility of this idea, calculate the necessary hydrogen content needed to self-ignite propane-air mixtures, and finally study the synergism of binary fuels.

Ignition of binary mixtures is not a new concept. For example, Deutschmann et al. (2000) computationally and experimentally studied the use of hydrogen combustion to ignite methane-air mixtures in a catalytic monolith. They found that the thermal release from the combustion of sufficiently fuel-rich hydrogen-air mixtures causes methane ignition. However, high temperatures limited their experimental study to initial transients only.

Hydrogen combustion can be employed to ignite propane-air, because the wall temperatures reached in hydrogen-air combustion are higher than the ignition temperature of propane. Which is referred to as hydrogen-assisted ignition of propane. In the present work, the thermal effect of hydrogen on hydrogen-assisted catalytic ignition is the main influence factor, because the concentration of hydrogen added is low. Therefore, the chemical effect is not consider in this work. Due to absence of detailed reaction mechanism of hydrogen-assisted catalytic ignition of propane-air mixtures, the variation of free radicals and the effect of hydrogen on the ignition temperature of propane are also not investigated in this work.

Here, we capitalize on the self-ignition of hydrogen at microscales and focus on the self-ignition of propane by adding hydrogen. There are different ways to carry out such simulation. One is to simultaneously start flowing all reagents. Another is to first start the hydrogen-air mixture followed by introduction of the hydrocarbon. In the present work, transient response of different feed methods (two startup methods of propane) is analyzed:

(a) Co-feed mode: premixed hydrogen-propane-air mixtures;

(b) Sequential feed mode: switched from hydrogen-air to propaneair mixtures.

The first method entails simultaneously turning on the flow of hydrogen, propane, and air until the propane ignites (co-feed mode), and then turning off the hydrogen flow and increasing the flow rates of propane and air so that the total flow rate remains constant throughout the simulation.

In the second method, hydrogen-air mixtures at the desired equivalence ratio are fed into the micro-combustor firstly. Once the sufficiently high temperature (ignition temperature of propane) has been reached, the hydrogen feed is cut off and the feed of propane-air mixtures is started. Simultaneously, keep total flow rate constant.

Norton and Vlachos (2005) performed experimental studies on hydrogen assisted self-ignition of propane-air mixtures in catalytic micro-combustors. They demonstrated that co-feed mode results in a faster heatup of the system as compared with sequential feed mode; cofeed mode is simple and has the additional benefit of heat release from both fuels; co-feeding hydrogen with propane appears as a good startup strategy. Therefore, comparison of the advantage and disadvantage between the co-feed and sequential feed modes is not taken into consideration. In the present work, a detailed study of hydrogenassisted propane catalytic combustion is performed for two modes of operation: co-feed and sequential feed modes.

\subsection{Co-Feed Mode}

The bifurcation behavior of propane catalytic ignition in hydrogenassisted co-feed mode are shown in Fig. 9. The inlet velocity is set to $10.0 \mathrm{~m} / \mathrm{s}$. The equivalence ratio (0.6 and 0.7$)$ of premixed propane-air mixtures is kept fixed. The flow rates of propane and air are decreased as the hydrogen concentration is increased starting from a zero value, while the hydrogen flow rate increases to maintain the total volumetric flow rate constant. As hydrogen concentration is increased, the maximum temperature increases gradually because of hydrogen combustion in the feed. Then, after a particular concentration of hydrogen, the heat released on hydrogen combustion is sufficient to ignite propane combustion and the turning point bifurcation is observed in Fig. 9. For comparison, the ignition temperatures in inlet feed preheating mode are also shown in Fig. 9. For the hydrogen-assisted ignition case, the maximum wall temperatures at the ignition bifurcation are slightly higher than the inlet preheating case.

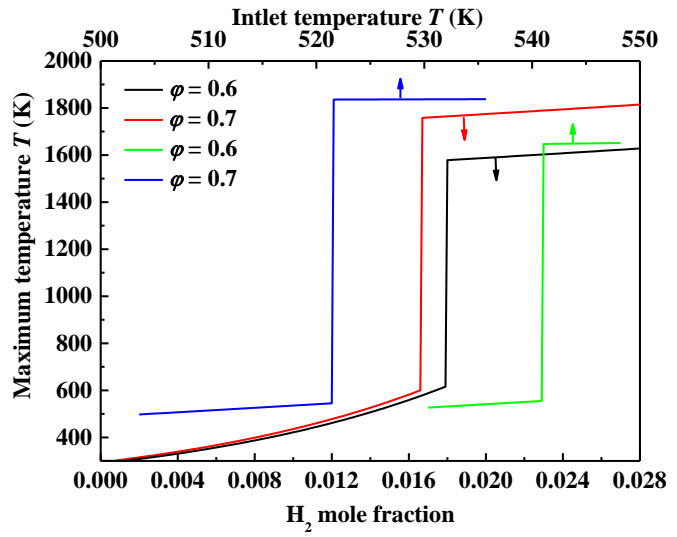

Fig. 9 The ignition turning point bifurcation in micro-combustors for catalytic propane-air ignition in hydrogen-assisted co-feed mode (black and red lines, bottom abscissa) and inlet preheating mode (green and blue lines, top abscissa).

The effect of inlet equivalence ratio on the hydrogen requirement for self-ignition is shown in Fig. 10. The inlet velocity is set to $10 \mathrm{~m} / \mathrm{s}$. For comparison, the ignition temperatures of propane without hydrogen addition in inlet feed preheating mode are also shown in Fig. 10. The hydrogen requirement in the feed reduces as the inlet equivalence ratio of propane-air is increased. For the hydrogen-assisted ignition case, the aforementioned trend is qualitatively similar to the inlet preheating case.

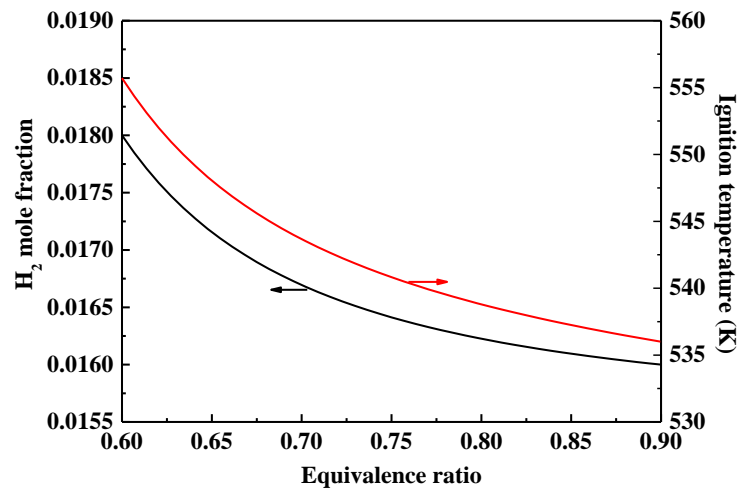

Fig. 10 The concentration of hydrogen required for ignition in hydrogen-assisted co-feed mode (black line, left ordinate) and the ignition temperature (red line, right ordinate) for different equivalence ratios of propane-air mixtures.

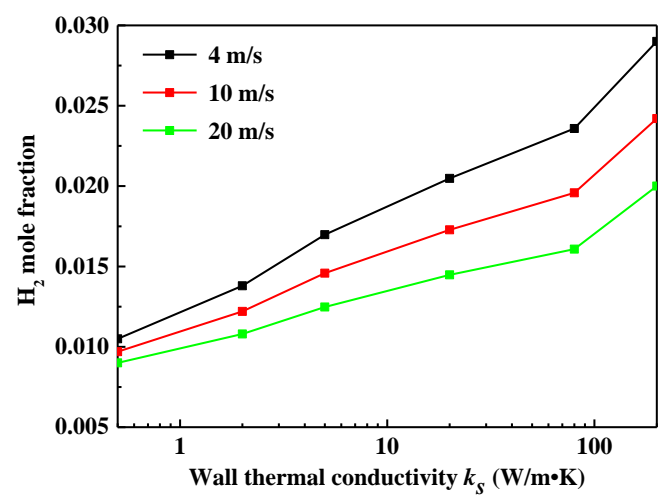

Fig. 11 The concentration of hydrogen required for ignition in hydrogen-assisted co-feed mode for different inlet velocities and wall thermal conductivities. $\varphi$ (propane) $=0.7, h=20 \mathrm{~W} / \mathrm{m}^{2} \cdot \mathrm{K}$, and $k_{s}=20 \mathrm{~W} / \mathrm{m} \cdot \mathrm{K}$. 
As observed in Fig. 11, inlet velocity and wall thermal conductivity both have strong effects on the concentration of hydrogen required for propane ignition. The wall temperatures increase as the inlet velocity is increased. Therefore, the concentration of hydrogen required for propane ignition decreases as the velocity is increased. Likewise, the concentration of hydrogen required for propane ignition decreases as the wall thermal conductivity is decreased. The reason is that the hot spots created near the inlet section for lower thermal conductivity material as observed in Fig. 2 help the hydrogen-propaneair mixtures get ignite with lesser hydrogen.

In the present work, the transient response of ignition in the cofeed mode is analyzed as follows.

The equivalence ratio $\varphi=0.7$ of premixed propane-air is kept fixed and the concentration of hydrogen required is 0.0005 excess of the minimum hydrogen concentration required for ignition. In the cofeed ignition mode, the transient responses of bulk gas phase temperature, interior wall temperature and propane conversion for three different values of wall thermal conductivity are shown in Fig. 12, 13 and 14 , respectively.

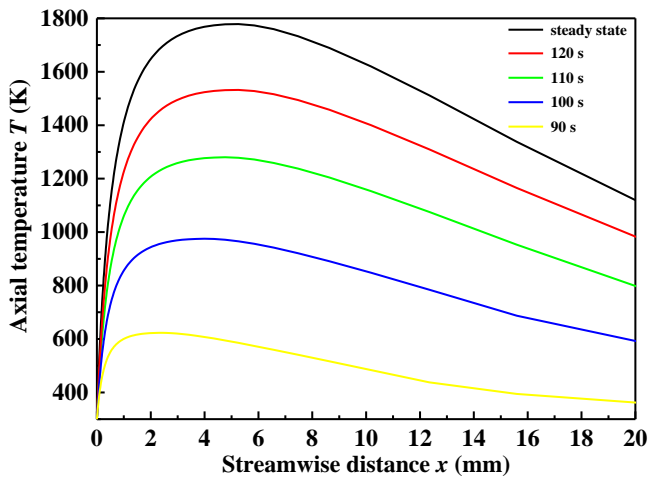

(a) $k_{s}=0.5 \mathrm{~W} / \mathrm{m} \cdot \mathrm{K}$

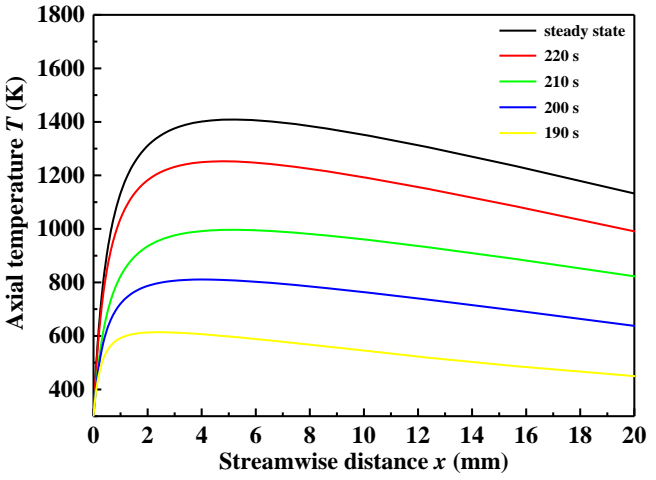

(b) $k_{s}=20 \mathrm{~W} / \mathrm{m} \cdot \mathrm{K}$

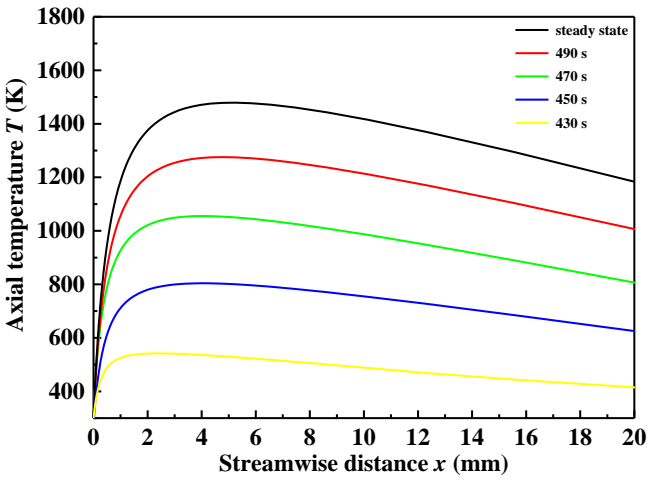

(c) $k_{s}=200 \mathrm{~W} / \mathrm{m} \cdot \mathrm{K}$

Fig. 12 Transient response of bulk gas phase temperature profiles for ignition in hydrogen-assisted co-feed mode for different wall thermal conductivities. $\varphi$ (propane) $=0.7, u_{0}=2 \mathrm{~m} / \mathrm{s}, h=20$ $\mathrm{W} / \mathrm{m}^{2} \cdot \mathrm{K}$, and $k_{s}=20 \mathrm{~W} / \mathrm{m} \cdot \mathrm{K}$.
As before, hydrogen combustion ignites in approximately 1.0-2.0 s and directly reaches its steady state profile (magenta line: hydrogen in Fig. 14). For most of the simulation time, note that the hydrogen conversion profiles do not show any noticeable change, and we solve the fully transient issue without making any pseudo-steady assumptions. At various different times, the axial variation in propane conversion is plotted in Fig. 14. The ignition time $\left(t_{i g n}\right)$ is defined as the time taken for propane conversion rate to reach $50 \%$ at the exit in catalytic microcombustors.

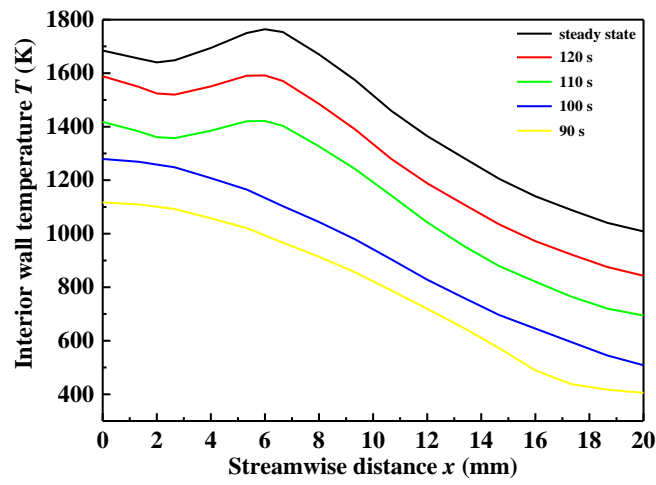

(a) $k_{s}=0.5 \mathrm{~W} / \mathrm{m} \cdot \mathrm{K}$

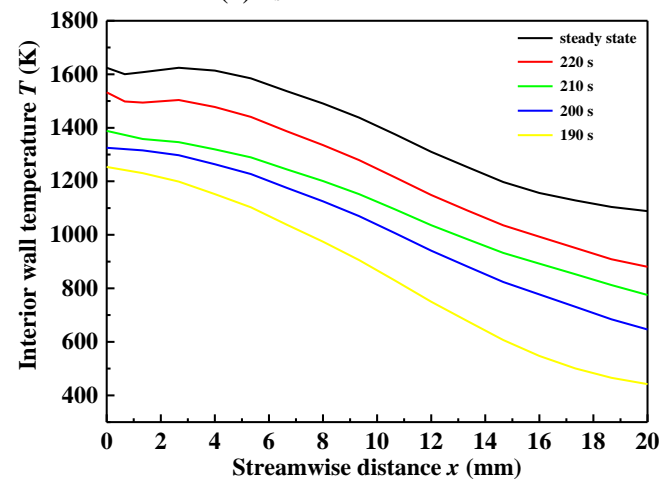

(b) $k_{s}=20 \mathrm{~W} / \mathrm{m} \cdot \mathrm{K}$

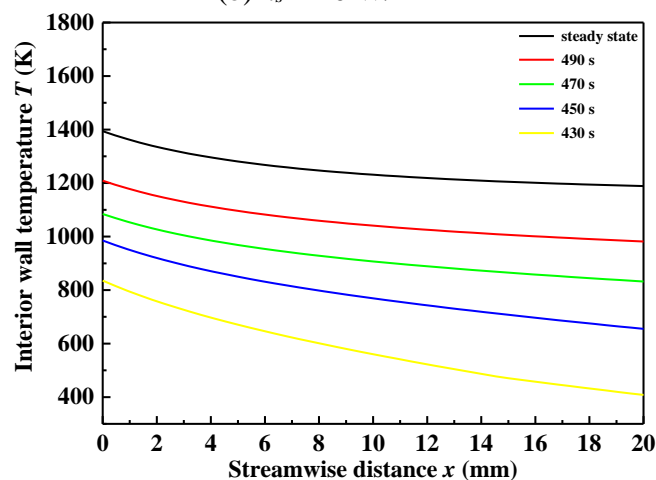

(c) $k_{s}=200 \mathrm{~W} / \mathrm{m} \cdot \mathrm{K}$

Fig. 13 Transient response of interior wall temperature profiles for ignition in hydrogen-assisted co-feed mode for different wall thermal conductivities. $\varphi$ (propane) $=0.7, u_{0}=2 \mathrm{~m} / \mathrm{s}, h=20$ $\mathrm{W} / \mathrm{m}^{2} \cdot \mathrm{K}$, and $k_{s}=20 \mathrm{~W} / \mathrm{m} \cdot \mathrm{K}$.

As the wall thermal conductivity is increased, the catalytic ignition time increases as observed in Fig. 14: from $98 \mathrm{~s}$ for insulating walls $(0.5$ $\mathrm{W} / \mathrm{m} \cdot \mathrm{K})$, to $202 \mathrm{~s}$ for moderately thermal conducting wall $(20 \mathrm{~W} / \mathrm{m} \cdot \mathrm{K})$, and $448 \mathrm{~s}$ for highly thermal conducting walls $(200 \mathrm{~W} / \mathrm{m} \cdot \mathrm{K})$. The aforementioned trend can be attributed to heat localization in the wall materials with low thermal conductivity, which leads to hot spot formation and faster ignition. In addition, in the co-feed ignition mode, the front-end ignition in catalytic micro-combustors is observed in all cases. Therefore, the bulk gas phase and interior wall temperatures (Fig. 12 and 13) reach their steady state values quickly once propane is 
ignited. Therefore, in the co-feed ignition mode, the catalytic combustion characteristics of hydrogen-assisted propane qualitatively resemble the selectively preheating initial portion of the combustion chamber wall.

As observed in Fig. 13, for low thermal conductivity walls $(0.5$ $\mathrm{W} / \mathrm{m} \cdot \mathrm{K})$, the interior wall temperatures first drop, then increase and then drop again at steady state. This trend is mostly because hydrogen combustion zone is located significantly upstream compared to propane. In the region between them, the interior wall temperatures drop slightly by reason of heat losses to the surroundings.

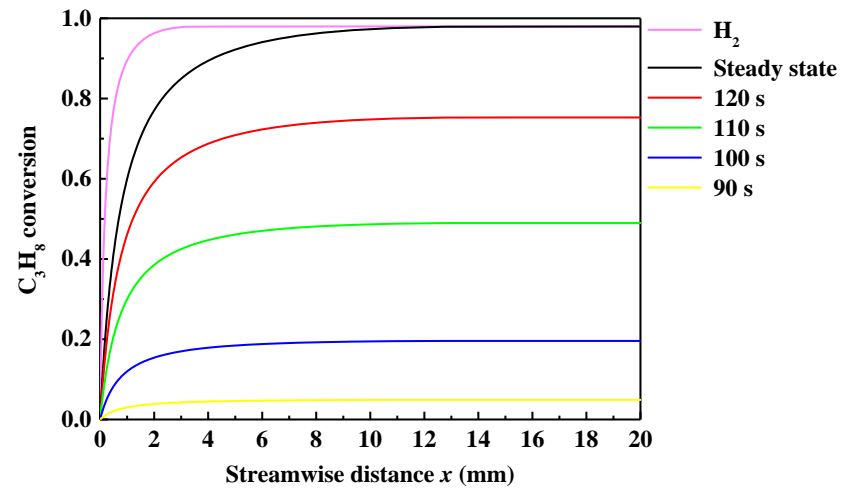

(a) $k_{s}=0.5 \mathrm{~W} / \mathrm{m} \cdot \mathrm{K}$

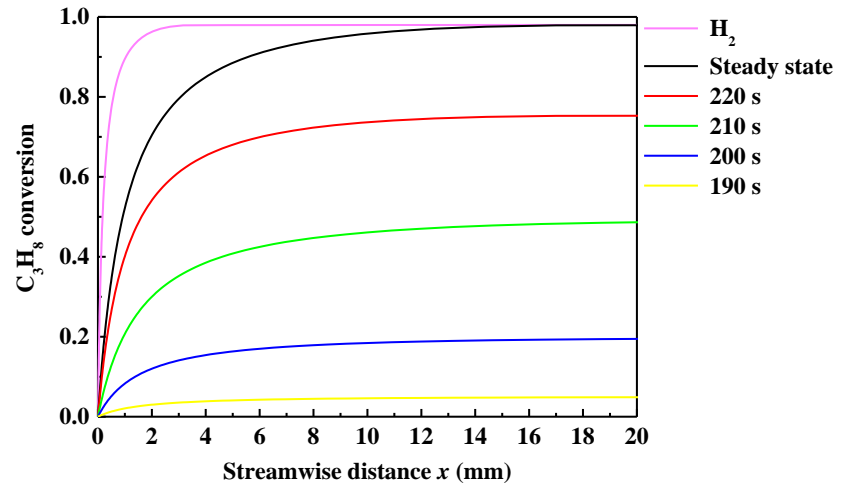

(b) $k_{s}=20 \mathrm{~W} / \mathrm{m} \cdot \mathrm{K}$

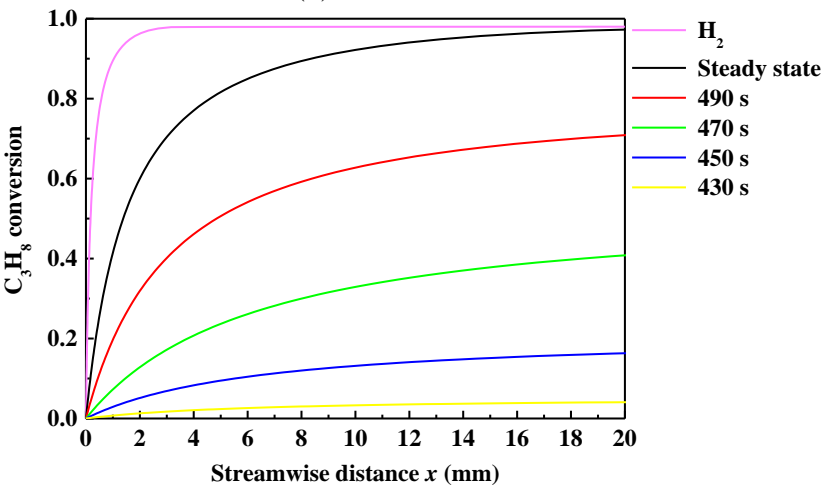

(c) $k_{s}=200 \mathrm{~W} / \mathrm{m} \cdot \mathrm{K}$

Fig. 14 Transient response of propane conversion profiles for ignition in hydrogen-assisted co-feed mode for different wall thermal conductivities. $\varphi$ (propane) $=0.7, u_{0}=2 \mathrm{~m} / \mathrm{s}, h=20 \mathrm{~W} / \mathrm{m}^{2} \cdot \mathrm{K}$, and $k_{s}=20 \mathrm{~W} / \mathrm{m} \cdot \mathrm{K}$.

The gas phase temperature and propane conversion vs. the cumulative time at the exit for different wall thermal conductivities are shown in Fig. 15. As observed, the triangles represent the ignition time $t_{i g n}$ at which propane is ignited, and the circles represent the steady state time $t_{s s}$ at which propane catalytic combustion taken to reach steady state.

In general, under lean combustion conditions, the premixed hydrogen-propane-air mixtures in co-feed mode can lead to ignition without the need for external heating. Hydrogen ignites instantaneously, and followed by propane ignition after propane ignition temperature is reached. These results are consistent with the conclusions from the previous works of Deutschmann et al. (2000), who experimentally investigated the hydrogen-assisted catalytic ignition characteristics of methane in a Pt-coated monolith reactor, and found that the main effect of hydrogen is thermal during ignition; the hydrogen ignited first on the surface of catalysts, and then the temperature of mixtures increased from room temperature to ignition point.

The concentration (on a molar basis) of hydrogen required for propane catalytic ignition varies in the range of $0.008-0.028$, and decreases for: lower wall thermal conductivity, higher inlet velocity, and higher equivalence ratio of propane-air mixtures.

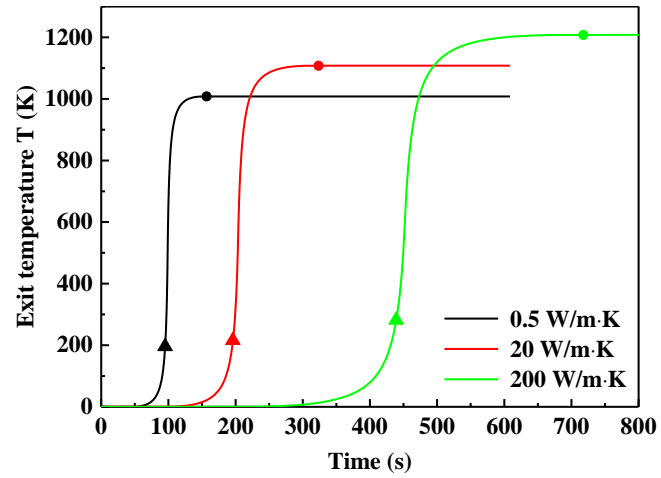

(a) Exit temperature

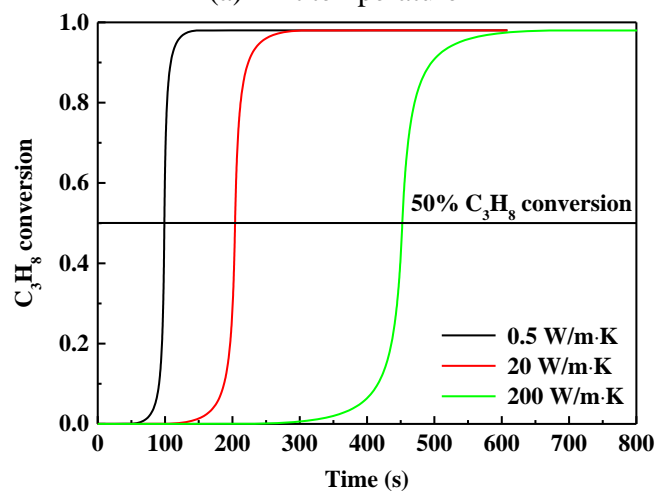

(b) Propane conversion

Fig. 15 Exit temperature and propane conversion profiles for ignition in hydrogen-assisted co-feed mode for different wall thermal conductivities. $\varphi$ (propane) $=0.7, u_{0}=2 \mathrm{~m} / \mathrm{s}, h=20 \mathrm{~W} / \mathrm{m}^{2} \cdot \mathrm{K}$, and $k_{s}=20 \mathrm{~W} / \mathrm{m} \cdot \mathrm{K}$. The triangles represent the ignition time $t_{i g n}$, and the circles represent the steady state time $t_{s s}$.

\subsection{Sequential Feed Mode}

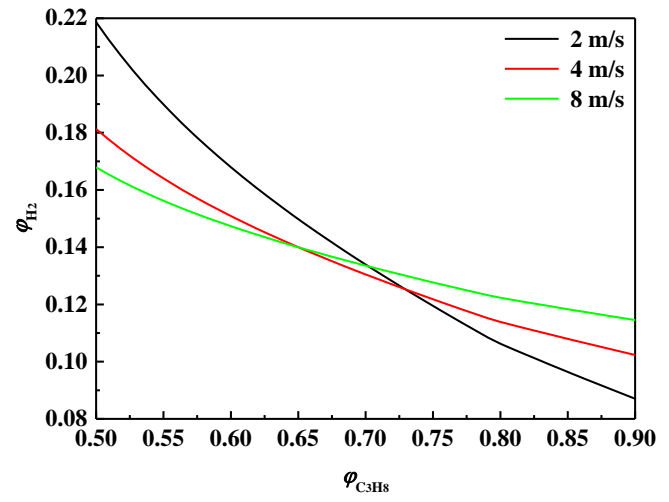

Fig. 16 The minimum equivalence ratio of hydrogen-air required for the propane ignition of a particular equivalence ratio of propaneair for different inlet velocities. 
In the sequential feed mode, effect of equivalence ratio of propane-air on the minimum equivalence ratio of hydrogen required for propane ignition for different inlet velocities is shown in Fig. 16. The minimum concentration of hydrogen required for propane ignition decreases as the equivalence ratio of propane-air is increased. For higher inlet velocity, the concentration of hydrogen required for propane ignition is expected to be lower in agreement with the previous section. The region below each curve represents that the hydrogen concentration is insufficient for propane ignition. While this behavior is existent at higher equivalence ratio of propane-air $(\varphi \mathrm{C} 3 \mathrm{H} 8>0.73)$, the situation is entirely different at lower equivalence ratio of propane-air $(\varphi \mathrm{C} 3 \mathrm{H} 8<$ 0.64). Note that the wall temperature is still higher as the velocity is increased, keeping equivalence ratio constant. However, the location of the combustion zone is pushed downstream at higher inlet velocities. This prevents stabilization of propane combustion when we switch over from hydrogen-air to propane-air inlet. Hence, we see a reversal in the trend at lower propane equivalence ratio.

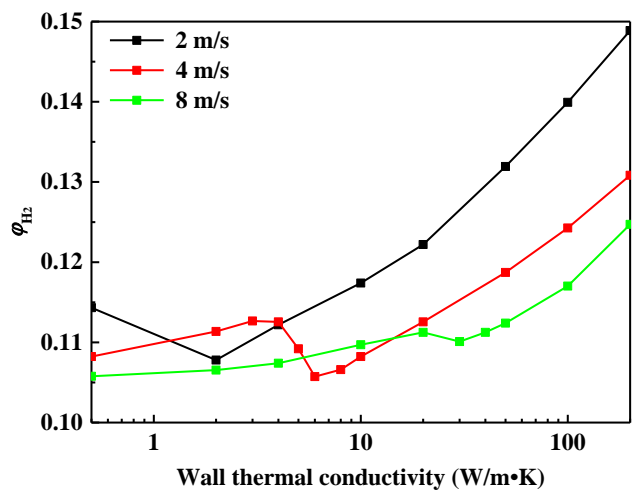

(a) Concentration of hydrogen required

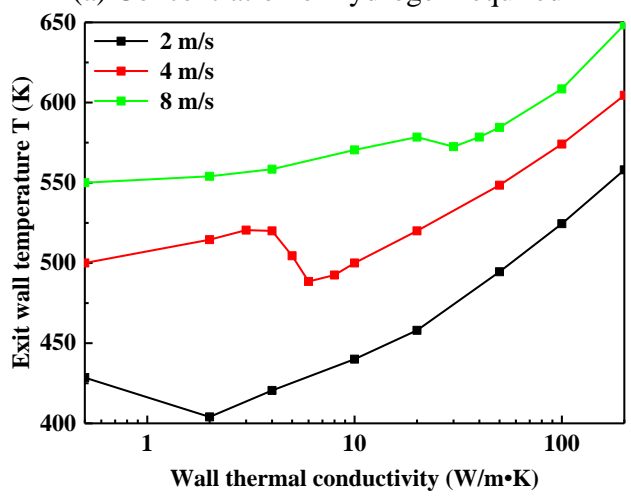

(b) Exit wall temperature

Fig. 17 Effect of wall thermal conductivity on exit wall temperature and the minimum concentration of hydrogen required for propane ignition for different inlet velocities.

Effect of wall thermal conductivity on exit wall temperature and the minimum concentration of hydrogen required for propane catalytic ignition for different inlet velocities are shown in Fig. 17. The exit wall temperature is the minimum wall temperature that should be attained before switching from hydrogen-air to propane-air mixtures to guarantee stable propane catalytic ignition through the parametric study.

In the sequential feed mode, as wall thermal conductivity is decreased, the concentration of hydrogen required decreases consistently with the co-feed mode results. However, this variation trend is not monotonic unlike the co-feed mode. Such as inlet velocity of $4 \mathrm{~m} / \mathrm{s}$, as the wall thermal conductivity is decreased until $6 \mathrm{~W} / \mathrm{m} \cdot \mathrm{K}$, the minimum concentration of hydrogen required decreases monotonically. However, as the wall thermal conductivity is further decreased to $0.5 \mathrm{~W} / \mathrm{m} \cdot \mathrm{K}$, the minimum concentration of hydrogen required increases slightly and then continue to decrease. Similar variation trends can be observed for the inlet velocities of 2 and $8 \mathrm{~m} / \mathrm{s}$ as well.

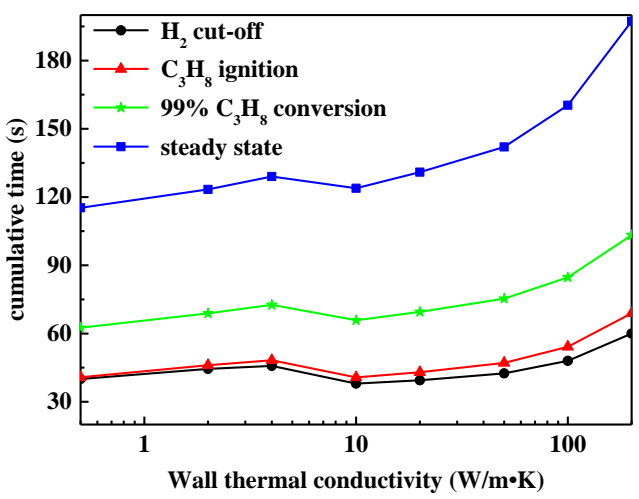

Fig. 18 Effect of wall thermal conductivity on hydrogen cut-off time, propane ignition time, $99 \%$ propane conversion and steady state time in the sequential feed mode. $\varphi$ (hydrogen) $=0.148, \varphi$ (propane, after hydrogen cut-off) $=0.7, u_{0}=2 \mathrm{~m} / \mathrm{s}, h=20$ $\mathrm{W} / \mathrm{m}^{2} \cdot \mathrm{K}$, and $k_{s}=20 \mathrm{~W} / \mathrm{m} \cdot \mathrm{K}$.

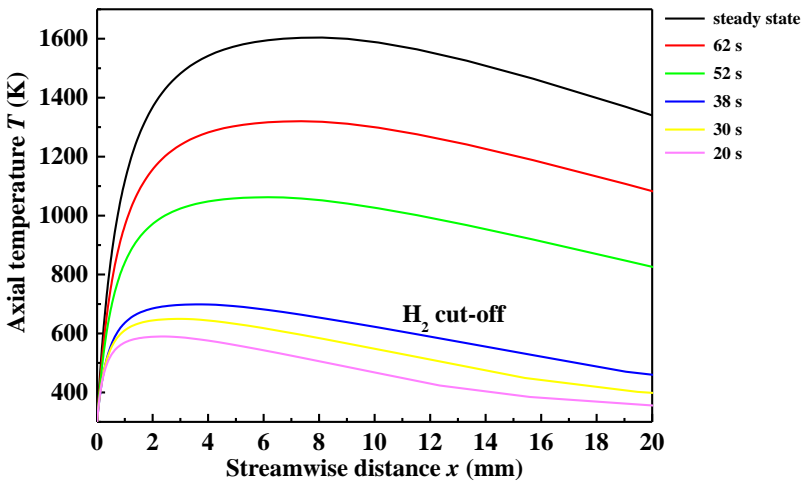

(a) $k_{s}=0.5 \mathrm{~W} / \mathrm{m} \cdot \mathrm{K}$

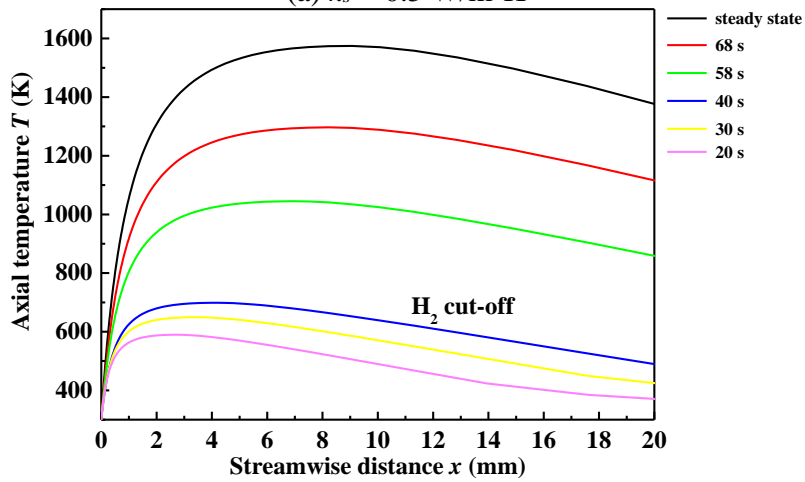

(b) $k_{s}=20 \mathrm{~W} / \mathrm{m} \cdot \mathrm{K}$

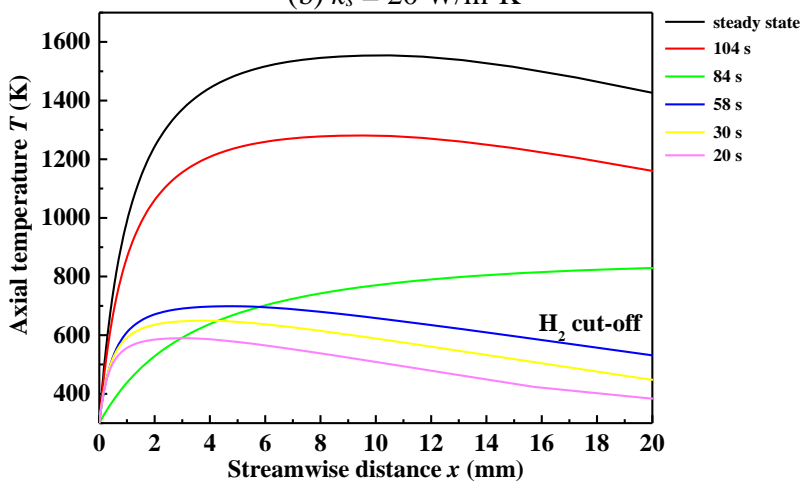

(c) $k_{s}=200 \mathrm{~W} / \mathrm{m} \cdot \mathrm{K}$

Fig. 19 Transient response of bulk gas phase temperature profiles in the sequential feed mode for different wall thermal conductivities. $\varphi$ (hydrogen $)=0.148, \varphi$ (propane, after hydrogen cut-off) $=0.7, u_{0}=2 \mathrm{~m} / \mathrm{s}, h=20 \mathrm{~W} / \mathrm{m}^{2} \cdot \mathrm{K}$, and $k_{s}=20 \mathrm{~W} / \mathrm{m} \cdot \mathrm{K}$. 
Effect of wall thermal conductivity on the hydrogen cut-off time, propane ignition time, $99 \%$ propane conversion and steady state time are shown in Fig. 18. For three different wall thermal conductivities $(0.5,20$ and $200 \mathrm{~W} / \mathrm{m} \cdot \mathrm{K})$, the temporal variations in bulk gas phase temperature, interior wall temperature and propane conversion profiles are shown in Fig. 19, 20 and 21. The flow is switched from hydrogenair to propane-air mixtures as the exit wall temperatures exceed the corresponding temperatures shown in Fig. 17 (b). The switch is represented as circles in Fig. 18 and by blue lines in Fig. 19.

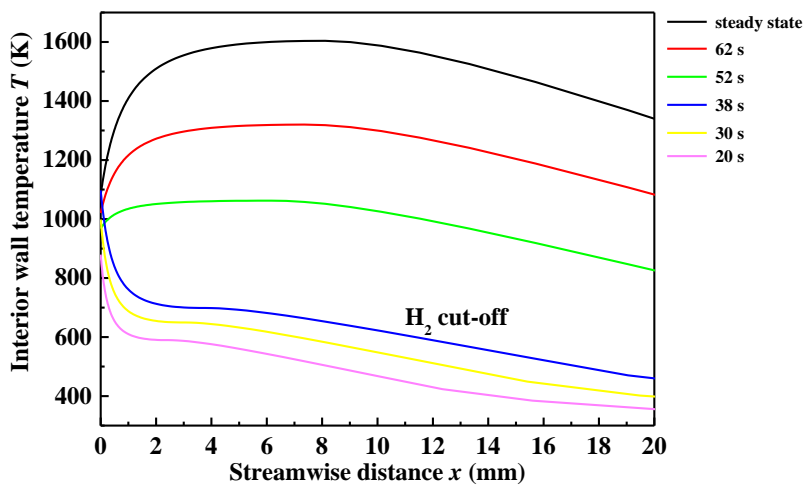

(a) $k_{s}=0.5 \mathrm{~W} / \mathrm{m} \cdot \mathrm{K}$

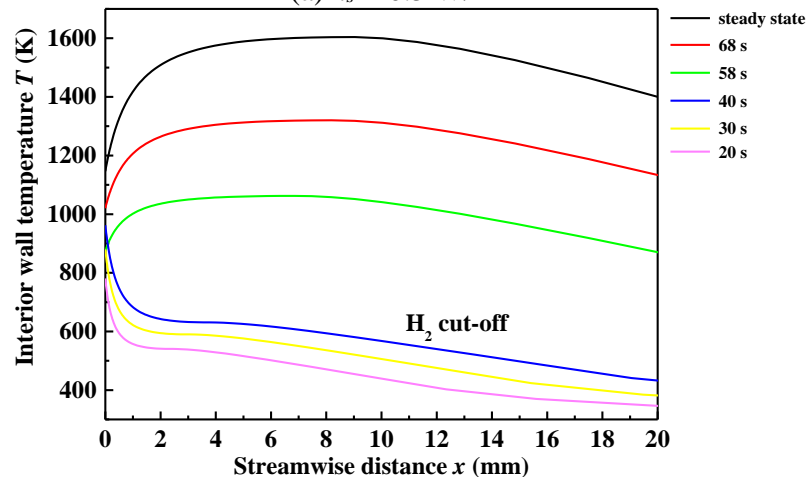

(b) $k_{s}=20 \mathrm{~W} / \mathrm{m} \cdot \mathrm{K}$

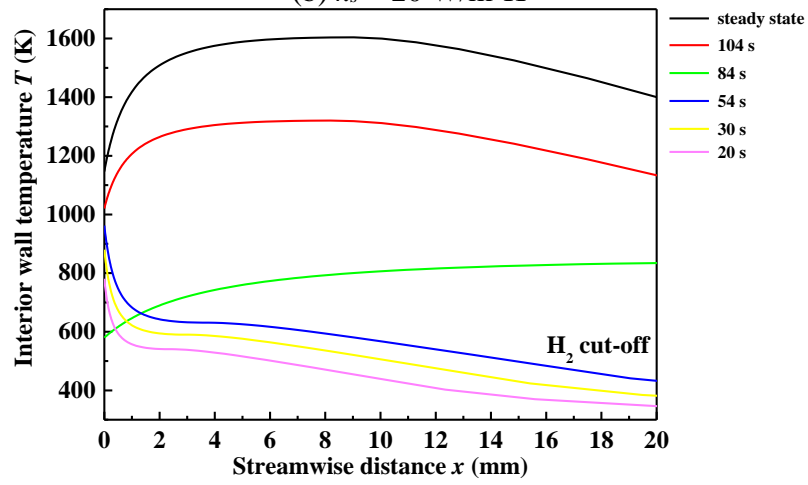

(c) $k_{s}=200 \mathrm{~W} / \mathrm{m} \cdot \mathrm{K}$

Fig. 20 Transient response of interior wall temperature profiles in the sequential feed mode for different wall thermal conductivities. $\varphi$ $($ hydrogen $)=0.148, \varphi$ (propane, after hydrogen cut-off $)=0.7, u_{0}=2$ $\mathrm{m} / \mathrm{s}, h=20 \mathrm{~W} / \mathrm{m}^{2} \cdot \mathrm{K}$, and $k_{s}=20 \mathrm{~W} / \mathrm{m} \cdot \mathrm{K}$.

The hydrogen cut-off times do not vary significantly $\left(40 \mathrm{~s} \leq t_{\text {cut-off }} \leq\right.$ $60 \mathrm{~s})$ as the wall thermal conductivity is increased. For all cases, propane ignition times require less than $10 \mathrm{~s}$ and $99 \%$ propane conversion is reached (as observed in Fig. 18) in a short time thereafter once the flow of propane-air mixtures is started. However, compared with lower thermal conductivity walls, the times taken to reach steady state are significantly higher for highly thermal conductivity walls. For low and moderate wall thermal conductivity values $(0.5$ and $20 \mathrm{~W} / \mathrm{m} \cdot \mathrm{K})$ as observed in Fig. 19, 20 and 21, the catalytic ignition characteristics are similar to partially preheating the initial segment of the micro- combustor. However, for high wall thermal conductivity values (200 $\mathrm{W} / \mathrm{m} \cdot \mathrm{K})$, the ignition characteristics are close to completely heating the catalytic micro-combustor wall, and the back-end ignition can be observed.

The cumulative propane emissions and exit gas temperature for different wall thermal conductivities are shown in Fig. 22. Initially, there are no propane emissions until propane flow is started. The propane emissions with sharp jump occurs between the switch time and 99\% propane conversion time (represented as circles in Fig. 22 (a)). Moreover, the exit gas temperature increases rapidly as the inlet flow is switched from lean hydrogen-air $(\varphi \mathrm{H} 2=0.148)$ to propane-air $(\varphi \mathrm{C} 3 \mathrm{H} 8=$ $0.7)$ mixtures. For high thermal conductivity walls $(200 \mathrm{~W} / \mathrm{m} \cdot \mathrm{K})$, Net propane emissions $(22.84 \mathrm{mg})$ at the end of $200 \mathrm{~s}$ increased by 3 times for low thermal conductivity walls $(5.54 \mathrm{mg}(0.5 \mathrm{~W} / \mathrm{m} \cdot \mathrm{K})$ and $5.58 \mathrm{mg}$ $(20 \mathrm{~W} / \mathrm{m} \cdot \mathrm{K}))$.

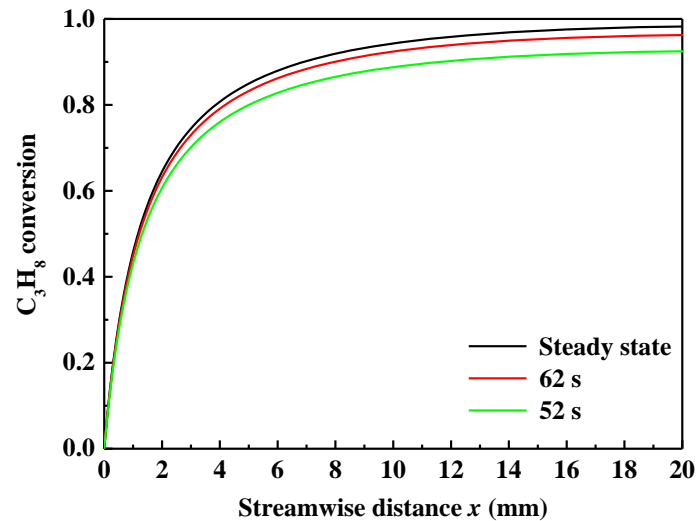

(a) $k_{s}=0.5 \mathrm{~W} / \mathrm{m} \cdot \mathrm{K}$

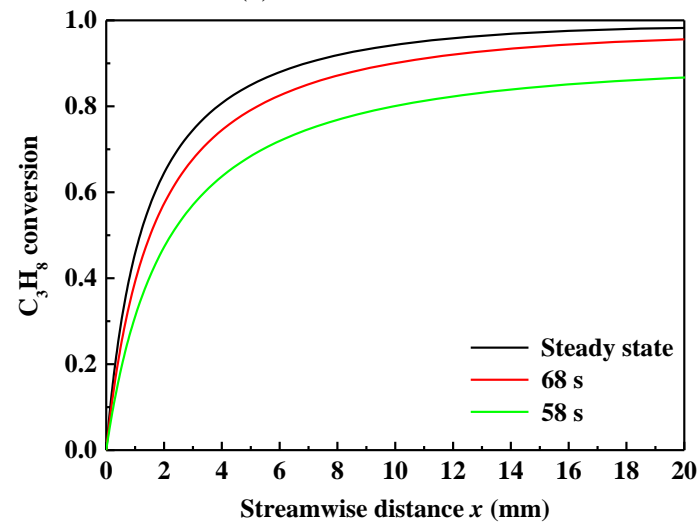

(b) $k_{s}=20 \mathrm{~W} / \mathrm{m} \cdot \mathrm{K}$

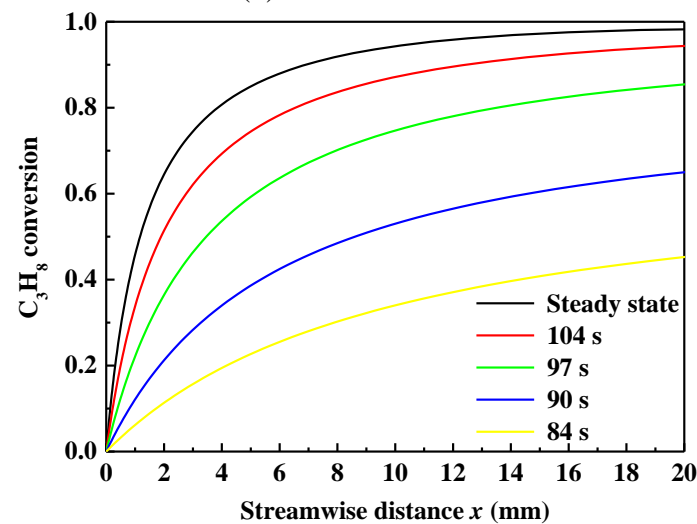

(c) $k_{s}=200 \mathrm{~W} / \mathrm{m} \cdot \mathrm{K}$

Fig. 21 Transient response of propane conversion profiles in the sequential feed mode for different wall thermal conductivities. $\varphi$ (hydrogen $)=0.148, \varphi$ (propane, after hydrogen cut-off $)=0.7, u_{0}=2$ $\mathrm{m} / \mathrm{s}, h=20 \mathrm{~W} / \mathrm{m}^{2} \cdot \mathrm{K}$, and $k_{s}=20 \mathrm{~W} / \mathrm{m} \cdot \mathrm{K}$. 


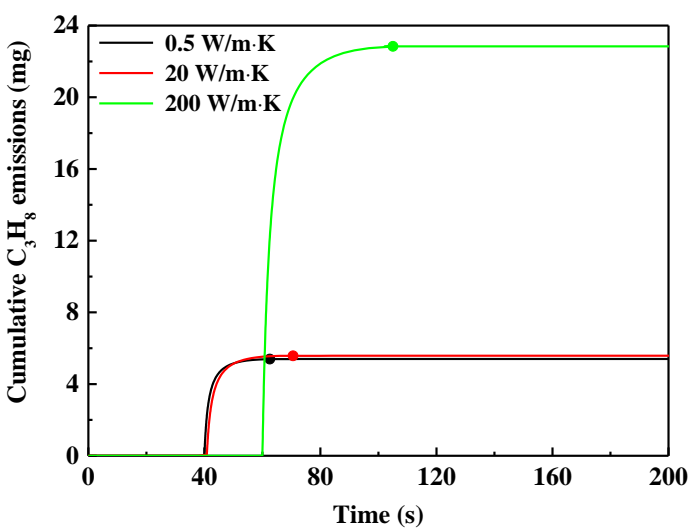

(a) Cumulative propane emissions

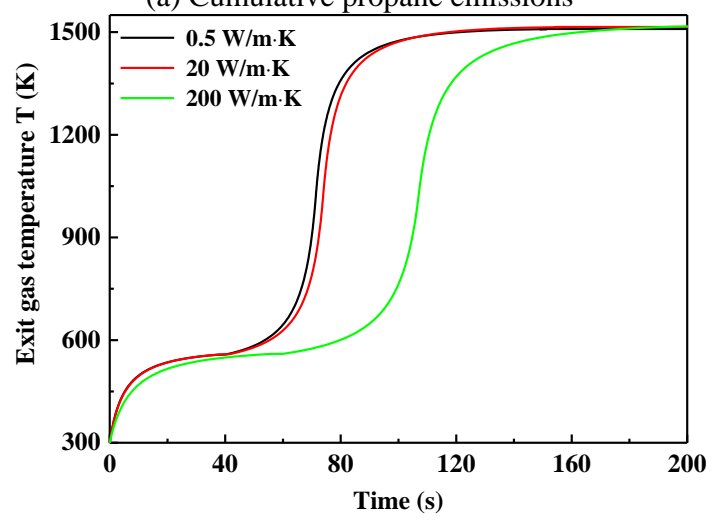

(b) Exit gas temperature

Fig. 22 Cumulative propane emissions and exit gas temperature in the sequential feed mode for different wall thermal conductivities. $\varphi$ (hydrogen $)=0.148, \varphi$ (propane, after hydrogen cut-off $)=0.7, u_{0}=2$ $\mathrm{m} / \mathrm{s}, h=20 \mathrm{~W} / \mathrm{m}^{2} \cdot \mathrm{K}$, and $k_{s}=20 \mathrm{~W} / \mathrm{m} \cdot \mathrm{K}$. Circles represent the time taken to reach $99 \%$ propane conversion in panel (a).

\section{CONCLUSIONS}

The addition of hydrogen to the initial mixture offers a way to light-off catalytic combustion of propane on $\mathrm{Pt} / \gamma-\mathrm{Al}_{2} \mathrm{O}_{3}$. In this study, for the steady and transient state, effect of wall thermal conductivity on hydrogen self-ignition and hydrogen-assisted ignition of propane-air mixtures in different feeding modes from ambient cold-start conditions were investigated numerically with chemical kinetic model in $\mathrm{Pt} / \gamma$ $\mathrm{Al}_{2} \mathrm{O}_{3}$ catalytic micro-combustors. The following conclusions were obtained from this micro-scale combustion characteristics study.

(1) Effect of wall thermal conductivity on the combustion and selfignition characteristics of hydrogen. Hydrogen conversion reaches the steady state in less than $1.0 \mathrm{~s}$ and front-end ignition is observed. Compared with the diffusion and reaction processes, the large thermal inertia of the micro-combustor solid structure leads to slow temperature dynamics, and transient response is dominated by the thermal inertia. The time required to reach steady state decreases with increasing inlet velocity and decreasing wall thermal conductivity. The heat localization in poorly conducting walls leads to fast ignition and shorter steady state time.

(2) Effect of wall thermal conductivity on catalytic ignition characteristics of hydrogen-assisted propane in the co-feed mode. The concentration (on a molar basis) of hydrogen required for propane ignition varies from 0.008 to 0.028 . The concentration of hydrogen required for propane ignition increased with increasing wall thermal conductivity, decreasing inlet velocity, and decreasing inlet equivalence ratio of propane-air mixtures. The combustion characteristics of hydrogen-assisted propane qualitatively resemble the selectively preheating initial portion of the combustion chamber wall. Hydrogen ignites instantaneously, and followed by propane ignition after propane ignition temperature is reached.

(3) Effect of wall thermal conductivity on catalytic ignition characteristics of hydrogen-assisted propane in the sequential feed mode. The wall thermal conductivity, inlet velocity, and inlet equivalence ratio of propane-air mixtures have significant effect on the concentration of hydrogen required for propane ignition. In general, the concentration of hydrogen required for propane ignition increased with increasing wall thermal conductivity, decreasing inlet velocity, and decreasing inlet equivalence ratio of propane-air mixtures. While this behavior is existent at higher wall thermal conductivity $\left(k_{s}>30 \mathrm{~W} / \mathrm{m} \cdot \mathrm{K}\right)$ for wall thermal conductivity and inlet velocity. The time taken to reach steady state, the hydrogen cut-off time, the propane ignition time and the cumulative propane emissions increased with increasing wall thermal conductivity. For low and moderate wall thermal conductivity values $(0.5$ and $20 \mathrm{~W} / \mathrm{m} \cdot \mathrm{K})$, the ignition characteristics are similar to partially preheating the initial segment of the micro-combustor. However, for high wall thermal conductivity values $(200 \mathrm{~W} / \mathrm{m} \cdot \mathrm{K})$, the ignition characteristics are close to completely heating the micro-combustor wall, and the back-end ignition can be observed.

\section{REFERENCES}

Ahn, J., Eastwood, C., Sitzki, L., and Ronney, P.D., 2005, "Gas-phase and catalytic combustion in heat-recirculating burners," Proceedings of the Combustion Institute, 30(2), 2463-2472.

http://dx.doi.org/10.1016/j.proci.2004.08.265

Aryafar, M., and Zaera, F., 1997, "Kinetic study of the catalytic oxidation of alkanes over nickel, palladium, and platinum foils," Catalysis Letters, 48(3-4), 173-183.

http://dx.doi.org/10.1023/a:1019055810760

Baigmohammadi, M., Sadeghi, S.S., Tabejamaat, S., and Zarvandi, J., 2013, "Numerical study of the effects of wire insertion on $\mathrm{CH}_{4}$ (methane)/air pre-mixed flame in a micro combustor," Energy, 54, 271-284.

http://dx.doi.org/10.1016/i.energy.2013.01.047

Bui, P.-A., Wilder, E., Vlachos, D., and Westmoreland, P., 1997, "Hierarchical reduced models for catalytic combustion: $\mathrm{H}_{2}$ /air mixtures near platinum surfaces," Combustion Science and Technology, 129(1-6), 243-275.

http://dx.doi.org/10.1080/00102209708935728

Cheekatamarla, P.K., Finnerty, C.M., and Cai, J., 2008, "Internal reforming of hydrocarbon fuels in tubular solid oxide fuel cells," International Journal of Hydrogen Energy, 33(7), 1853-1858. http://dx.doi.org/10.1016/j.ijhydene.2008.02.004

Chen, G.-B., Chen, C.-P., Wu, C.-Y., and Chao, Y.-C., 2007, "Effects of catalytic walls on hydrogen/air combustion inside a micro-tube," Applied Catalysis a-General, 332(1), 89-97.

http://dx.doi.org/10.1016/j.apcata.2007.08.011

Deshmukh, S.R., Mhadeshwar, A.B., and Vlachos, D.G., 2004, "Microreactor modeling for hydrogen production from ammonia decomposition on ruthenium," Industrial \& Engineering Chemistry Research, 43(12), 2986-2999.

http://dx.doi.org/10.1021/ie030557y

Deutschmann, O., Maier, L.I., Riedel, U., Stroemman, A.H., and Dibble, R.W., 2000, "Hydrogen assisted catalytic combustion of methane on platinum," Catalysis Today, 59(1-2), 141-150. http://dx.doi.org/10.1016/s0920-5861(00)00279-0

Fanaee, S.A., and Esfahani, J.A., 2014, "Two-dimensional analytical model of flame characteristic in catalytic micro-combustors for a 
hydrogen-air mixture," International Journal of Hydrogen Energy, 39(9), 4600-4610.

http://dx.doi.org/10.1016/j.ijhydene.2013.12.191

Federici, J.A., Wetzel, E.D., Geil, B.R., and Vlachos, D.G., 2009, "Single channel and heat recirculation catalytic microburners: An experimental and computational fluid dynamics study," Proceedings of the Combustion Institute, 32(2), 3011-3018.

http://dx.doi.org/10.1016/j.proci.2008.07.005

Gomez, A., Berry, J.J., Roychoudhury, S., Coriton, B., and Huth, J., 2007, "From jet fuel to electric power using a mesoscale, efficient Stirling cycle," Proceedings of the Combustion Institute, 31(2), 32513259.

http://dx.doi.org/10.1016/j.proci.2006.07.203

Groppi, G., Belloli, A., Tronconi, E., and Forzatti, P., 1995, “A comparison of lumped and distributed models of monolith catalytic combustors," Chemical Engineering Science, 50(17), 2705-2715. http://dx.doi.org/10.1016/0009-2509(95)00099-q

Hsueh, C.-Y., Chu, H.-S., Yan, W.-M., Leu, G.-C., and Tsai, J.-I., 2011, "Three-dimensional analysis of a plate methanol steam micro-reformer and a methanol catalytic combustor with different flow channel designs," International Journal of Hydrogen Energy, 36(21), 1357513586.

http://dx.doi.org/10.1016/j.ijhydene.2011.07.099

Hua, J., Wu, M., and Kumar, K., 2005, "Numerical simulation of the combustion of hydrogen-air mixture in micro-scaled chambers. Part I: fundamental study," Chemical Engineering Science, 60(13), 3497-3506. http://dx.doi.org/10.1016/j.ces.2005.01.041

Jin, J., and Kwon, S., 2009, "Microcatalytic combustion of $\mathrm{H}_{2}$ on $\mathrm{Pt} / \mathrm{Al}_{2} \mathrm{O}_{3}$-coated nickel foam," Combustion Science and Technology, 181(2), 211-225.

http://dx.doi.org/10.1080/00102200802424526

Ju, Y., and Choi, C.W., 2003, “An analysis of sub-limit flame dynamics using opposite propagating flames in mesoscale channels," Combustion and Flame, 133(4), 483-493.

http://dx.doi.org/10.1016/s0010-2180(03)00058-0

Ju, Y., and Maruta, K., 2011, "Microscale combustion: technology development and fundamental research," Progress in Energy and Combustion Science, 37(6), 669-715.

http://dx.doi.org/10.1016/j.pecs.2011.03.001

Kaisare, N.S., Deshmukh, S.R., and Vlachos, D.G., 2008, "Stability and performance of catalytic microreactors: Simulations of propane catalytic combustion on Pt," Chemical Engineering Science, 63(4), 1098-1116.

http://dx.doi.org/10.1016/j.ces.2007.11.014

Kaisare, N. S., Lee, J. H., and Fedorov, A. G., 2005, "Hydrogen generation in a reverse-flow microreactor: 1. Model formulation and scaling," AICHE Journal, 51(8), 2254-2264.

http://dx.doi.org/10.1002/aic.10492

Kaisare, N.S., and Vlachos, D.G., 2007, "Extending the region of stable homogeneous micro-combustion through forced unsteady operation," Proceedings of the Combustion Institute, 31(2), 3293-3300.

http://dx.doi.org/10.1016/j.proci.2006.07.031

Kaisare, N.S., and Vlachos, D.G., 2007, "Optimal reactor dimensions for homogeneous combustion in small channels," Catalysis Today, 120(1), 96-106.

http://dx.doi.org/10.1016/j.cattod.2006.07.036

Kamada, T., Nakamura, H., Tezuka, T., Hasegawa, S., and Maruta, K., 2014, "Study on combustion and ignition characteristics of natural gas components in a micro flow reactor with a controlled temperature profile," Combustion and Flame, 161(1), 37-48.

\section{http://dx.doi.org/10.1016/j.combustflame.2013.08.013}

Karagiannidis, S., and Mantzaras, J., 2010, "Numerical investigation on the start-up of methane-fueled catalytic microreactors," Combustion and Flame, 157(7), 1400-1413.

http://dx.doi.org/10.1016/j.combustflame.2010.01.008

Karagiannidis, S., Mantzaras, J., Jackson, G., and Boulouchos, K., 2007, "Hetero-/homogeneous combustion and stability maps in methanefueled catalytic microreactors," Proceedings of the Combustion Institute, 31(2), 3309-3317.

http://dx.doi.org/10.1016/j.proci.2006.07.121

Karim, A.M., Federici, J.A., and Vlachos, D.G., 2008, "Portable power production from methanol in an integrated thermoeletric/microreactor system," Journal of Power Sources, 179(1), 113-120.

http://dx.doi.org/10.1016/j.jpowsour.2007.12.119

Kikas, T., Bardenshteyn, I., Williamson, C., Ejimofor, C., Puri, P., and Fedorov, A. G., 2003, "Hydrogen production in a reverse-flow autothermal catalytic microreactor: From evidence of performance enhancement to innovative reactor design," Industrial \& Engineering Chemistry Research, 42(25), 6273-6279.

http://dx.doi.org/10.1021/ie030021c

Kim, K.T., Lee, D.H., and Kwon, S., 2006, "Effects of thermal and chemical surface-flame interaction on flame quenching," Combustion and Flame, 146(1-2), 19-28.

http://dx.doi.org/10.1016/i.combustflame.2006.04.012

Kim, N.I., and Maruta, K., 2006, "A numerical study on propagation of premixed flames in small tubes," Combustion and Flame, 146(1-2), 283-301.

http://dx.doi.org/10.1016/j.combustflame.2006.03.004

Leach, T.T., and Cadou, C.P., 2005, "The role of structural heat exchange and heat loss in the design of efficient silicon microcombustors," Proceedings of the Combustion Institute, 30(2), 24372444.

http://dx.doi.org/10.1016/j.proci.2004.08.229

Leu, C.-H., King, S.-C., Huang, J.-M., Chen, C.-C., Tzeng, S.-S., Lee, C.-I., Chang, W.-C., and Yang, C.-C., 2013, "Visible images of the catalytic combustion of methanol in a micro-channel reactor," Chemical Engineering Journal, 226(0), 201-208.

http://dx.doi.org/10.1016/j.cej.2013.04.040

Mantzaras, J., 2008, "Catalytic combustion of syngas," Combustion Science and Technology, 180(6), 1137-1168.

http://dx.doi.org/10.1080/00102200801963342

Mantzaras, J., and Benz, P., 1999, “An asymptotic and numerical investigation of homogeneous ignition in catalytically stabilized channel flow combustion," Combustion and Flame, 119(4), 455-472. http://dx.doi.org/10.1016/s0010-2180(99)00071-1

Maruta, K., Takeda, K., Ahn, J., Borer, K., Sitzki, L., Ronney, P.D., and Deutschmann, O., 2002, "Extinction limits of catalytic combustion in microchannels," Proceedings of the Combustion Institute, 29(1), 957963.

http://dx.doi.org/10.1016/s1540-7489(02)80121-3

Men, Y., Kolb, G., Zapf, R., Pennemann, H., and Hessel, V., 2009, "Total combustion of propane in a catalytic microchannel combustor," Chemical Engineering Research \& Design, 87(1A), 91-96. http://dx.doi.org/10.1016/j.cherd.2008.07.010

Norton, D.G., and Vlachos, D.G., 2003, "Combustion characteristics and flame stability at the microscale: a CFD study of premixed methane/air mixtures," Chemical Engineering Science, 58(21), 48714882.

http://dx.doi.org/10.1016/j.ces.2002.12.005 
Norton, D.G., and Vlachos, D.G., 2004, “A CFD study of propane/air microflame stability," Combustion and Flame, 138(1-2), 97-107. http://dx.doi.org/10.1016/i.combustflame.2004.04.004

Norton, D.G., and Vlachos, D.G., 2005, "Hydrogen assisted selfignition of propane/air mixtures in catalytic microburners," Proceedings of the Combustion Institute, 30(2), 2473-2480. http://dx.doi.org/10.1016/j.proci.2004.08.188

Norton, D.G., Wetzel, E.D., and Vlachos, D.G., 2004, "Fabrication of single-channel catalytic microburners: effect of confinement on the oxidation of hydrogen/air mixtures," Industrial \& Engineering Chemistry Research, 43(16), 4833-4840.

http://dx.doi.org/10.1021/ie049798b

Raimondeau, S., Norton, D., Vlachos, D.G., and Masel, R. I., 2002, "Modeling of high-temperature microburners," Proceedings of the Combustion Institute, 29(1), 901-907. http://dx.doi.org/10.1016/s1540-7489(02)80114-6

Rana, U., Chakraborty, S., and Som, S.K., 2014, "Thermodynamics of premixed combustion in a heat recirculating micro combustor," Energy, 68, 510-518.

http://dx.doi.org/10.1016/j.energy.2014.02.070

Ronney, P.D., 2003, "Analysis of non-adiabatic heat-recirculating combustors," Combustion and Flame, 135(4), 421-439.

http://dx.doi.org/10.1016/j.combustflame.2003.07.003

Sari, A., and Zohrabian, A., 2014, "Simulation study of the effect of feed moisture on autothermal reforming in short contact time catalytic micro channels," International Journal of Hydrogen Energy, 39(7), 3269-3285.

http://dx.doi.org/10.1016/j.ijhydene.2013.12.105

Schneider, A., Mantzaras, J., and Eriksson, S., 2008, "Ignition and extinction in catalytic partial oxidation of methane-oxygen mixtures with large $\mathrm{H}_{2} \mathrm{O}$ and $\mathrm{CO}_{2}$ dilution," Combustion Science and Technology, 180(1), 89-126.

http://dx.doi.org/10.1080/00102200701487087

Schultze, M., Mantzaras, J., Bombach, R., and Boulouchos, K., 2013, "An experimental and numerical investigation of the hetero/homogeneous combustion of fuel-rich hydrogen/air mixtures over platinum," Proceedings of the Combustion Institute, 34(2), 2269-2277. http://dx.doi.org/10.1016/j.proci.2012.05.029
Sen, I., and Avci, A. K., 2014, "Simulation of exhaust gas reforming of propane in a heat exchange integrated microchannel reactor," International Journal of Hydrogen Energy, 39(2), 844-852. http://dx.doi.org/10.1016/j.ijhydene.2013.10.148

Stefanidis, G.D., and Vlachos, D.G., 2009, "Controlling homogeneous chemistry in homogeneous-heterogeneous reactors: application to propane combustion," Industrial \& Engineering Chemistry Research, 48(13), 5962-5968.

http://dx.doi.org/10.1021/ie801480m

Veeraragavan, A., and Cadou, C.P., 2011, "Flame speed predictions in planar micro/mesoscale combustors with conjugate heat transfer," Combustion and Flame, 158(11), 2178-2187. http://dx.doi.org/10.1016/j.combustflame.2011.04.006

Volchko, S.J., Sung, C.J., Huang, Y.M., and Schneider, S.J., 2006, "Catalytic combustion of rich methane/oxygen mixtures for micropropulsion applications," Journal of Propulsion and Power, 22(3), 684-693.

http://dx.doi.org/10.2514/1.19809

Yang, W., Deng, C., Zhou, J., Liu, J., Wang, Y., and Cen, K., 2014, "Experimental and numerical investigations of hydrogen-air premixed combustion in a converging-diverging micro tube," International Journal of Hydrogen Energy, 39(7), 3469-3476.

http://dx.doi.org/10.1016/j.ijhydene.2013.12.102

Zarvandi, J., Tabejamaat, S., and Baigmohammadi, M., 2012, "Numerical study of the effects of heat transfer methods on $\mathrm{CH}_{4} /\left(\mathrm{CH}_{4}+\right.$ $\mathrm{H}_{2}$ )-air pre-mixed flames in a micro-stepped tube," Energy, 44(1), 396409.

http://dx.doi.org/10.1016/j.energy.2012.06.015

Zhang, Y., Zhou, J., Yang, W., Liu, M., and Cen, K., 2007, "Effects of hydrogen addition on methane catalytic combustion in a microtube," International Journal of Hydrogen Energy, 32(9), 1286-1293. http://dx.doi.org/10.1016/j.ijhydene.2006.07.023

Zhou, J., Wang, Y., Yang, W., Liu, J., Wang, Z., and Cen, K., 2009, "Combustion of hydrogen-air in catalytic micro-combustors made of different material," International Journal of Hydrogen Energy, 34(8), 3535-3545.

http://dx.doi.org/10.1016/j.ijhydene.2009.01.032 